\title{
Annual Cycle of Rainfall in the Western North Pacific and East Asian Sector
}

\author{
CHIA CHOU \\ Research Center for Environmental Changes, Academia Sinica, and Department of Atmospheric Sciences, \\ National Taiwan University, Taipei, Taiwan \\ Li-FAN HUANG \\ Research Center for Environmental Changes, Academia Sinica, Taipei, Taiwan \\ LISHAN TSENG \\ Department of Earth Sciences, National Taiwan Normal University, Taipei, Taiwan \\ JIEN-YI TU \\ Department of Atmospheric Sciences, Chinese Culture University, Taipei, Taiwan \\ PEI-HuA TAN \\ Department of History and Geography, National Chiayi University, Chiayi, Taiwan
}

(Manuscript received 19 March 2008, in final form 29 October 2008)

\begin{abstract}
The annual cycle of precipitation over the western North Pacific and East Asian (WNP-EA) sector has five major periods: spring, the first and second wet periods, fall, and winter. In this study, processes that induce precipitation in each period are examined from a large-scale point of view. The wet phase over this sector has two distinct periods, which are dominated by the Asian summer monsoon circulation induced by the land-ocean contrast of net energy into the atmospheric column $\left(F^{\text {net }}\right)$. In the first wet period, the pre-mei-yu/mei-yu rainband is directly associated with a moisture flux convergence caused by the southwesterly Asian summer monsoon flow and the southeasterly trade winds, and indirectly associated with a dynamic feedback induced by this horizontal moisture convergence. The tropical convection, in the meantime, is associated with a rising motion that is induced by positive $F^{\text {net }}$. In the second wet period, the WNP summer monsoon gyre dominates the rainfall of this region, which is partially associated with warmer local sea surface temperature (SST) via positive $F^{\text {net }}$. The land-sea contrast of $F^{\text {net }}$ and the atmosphere-ocean interaction also play an important role in establishing the monsoon gyre. The dry phase over the WNP-EA region is the winter period in which precipitation is associated with winter storm activities and large-scale lifting associated with a pressure surge. In the two transition phases, due to a difference in heat capacity, the atmosphere and ocean have distinct impacts on precipitation, albeit similar solar insolations during the two periods. In the spring period, the atmospheric condition is favorable for convection, while the ocean surface is relatively colder, so the horizontal moisture advection associated with the westward extent of the Pacific subtropical high, which is different from a typical winter frontal system, is a major source for the spring rain. In the fall period, however, the atmospheric conditions dominated by the Asian winter monsoon circulation suppress convection, while relatively warmer SST still maintains tropical convection over the southern part of the WNP-EA region. Over the northern part of the WNP-EA region, the fall precipitation is associated with frontal systems, similar to those in winter.
\end{abstract}

Corresponding author address: Chia Chou, Research Center for Environmental Changes, Academia Sinica, P.O. Box 1-48, Taipei 11529, Taiwan.

E-mail: chiachou@rcec.sinica.edu.tw

\section{Introduction}

Rainfall is an important factor in describing a regional climate given its substantial impact on human life. Rainfall distribution is extremely inhomogeneous and localized. However, rainfall from a climatological point 
of view is usually controlled by large-scale phenomena. For instance, the Asian monsoon system dominates the precipitation over the western North Pacific and East Asian (WNP-EA) sector, our current area of interest. This monsoon system has a strong annual cycle, with a wet season in the boreal summer, a dry season in the boreal winter, and two transition seasons between the wet and dry seasons. This annual variation is termed "the slow annual cycle," which is commonly associated with solar insolation (e.g., LinHo and Wang 2002, hereafter LW02). A well-known feature of double peaks of heavy rainfall in the wet phase is usually found over the WNP-EA sector. The first peak is associated with the mei-yu-baiu rainfall, and the second with the WNP summer monsoon and typhoon rainfall. This variation within the wet phase of the Asian monsoon system is termed the fast annual cycle (Ding and Chan 2005; LW02). Thus, five natural rainy periods associated with the annual cycle are usually found over the WNP-EA sector (Chen and Chen 2003; LW02; Yeh and Chen 2000).

The Asian summer monsoon system includes several subregional systems - the Indian, East Asian, and WNP summer monsoons (Wang and LinHo 2002) — and covers the major rainy season over this region, so there have been many studies that have focused on this rainy period (e.g., Annamalai et al. 1999; Chou 2003; Ding 1992; Ding and Chan 2005; Li and Yanai 1996; Murakami 1987; Webster et al. 1998; Yasunari and Seki 1992 and references therein). In contrast, relatively less attention has been given to the rainfall variations in the other periods such as winter, fall, and spring. Nevertheless, the precipitation variations in these seasons merit further investigation. For instance, the spring rain in this region has a distinct characteristic; its rainfall is also very significant (Tian and Yasunari 1998). Some studies (Hung et al. 2004; Jiang et al. 2003) show that the spring rainfall over the WNP-EA has a strong interannual variation associated with El Niño-Southern Oscillation (ENSO) and an interdecadal variation associated with the Pacific decadal oscillation (PDO). Other studies (e.g., Chou 2004; Lau and Nath 2006; Wang et al. 2000; Wu et al. 2003; Zhang et al. 1996,1999; Zhang and Sumi 2002) also showed the relationship between rainfall over the WNP-EA region and ENSO in different seasons. Thus, before studying such interannual and interdecadal variabilities, processes that are associated with the precipitation over the WNP-EA sector on the scale of the annual cycle should be understood first.

In this study, we focus on the annual cycle of precipitation over the WNP-EA sector, the South China Sea, the WNP, and East Asia in particular. Processes that are associated with precipitation over this region are examined from a large-scale point of view. The understanding of the annual cycle can then help us further examine the interannual variations of precipitation over this sector; these variations are discussed in another study (Chou et al. 2009). The datasets and a climate model used in this study are introduced in section 2. Based on observations, we classify and describe precipitation periods and patterns for each period in section 3. Section 4 focuses on processes associated with the precipitation of the wet phase over the WNP-EA sector. The observed moisture and moist static energy (MSE) budgets are analyzed first. A climate model is then used to examine these mechanisms. Section 5 discusses the precipitation processes for the dry phase. The precipitation processes in the two transition phases are discussed in section 6 , followed by discussion and conclusions.

\section{Data and model}

\section{a. Data}

To capture much finer variations in the annual cycle of precipitation over the WNP-EA region, data with a pentad or finer temporal resolution are used here instead of monthly data, which are often used for studying the annual cycle. The precipitation dataset that is used in this study is that of the Climate Precipitation Center (CPC) Merged Analysis of Precipitation (CMAP; Xie and Arkin 1997). The CMAP precipitation dataset has global coverage from 1979 to 2006. Other fields, such as winds and heat fluxes, are derived from 28-yr (19792006) 6-hourly National Centers for Environmental Prediction-Department of Energy (NCEP-DOE) Reanalysis-2 data (hereafter referred to as NCEP2; Kanamitsu et al. 2002) with a resolution of $2.5^{\circ} \times 2.5^{\circ}$. To be consistent with the CMAP precipitation, a weekly optimum interpolation (OI) sea surface temperature (SST) with $1^{\circ}$ spatial resolution from November 1981 to December 2006 (Reynolds et al. 2002) is interpolated into a pentad resolution.

\section{b. Model}

To understand the mechanisms involved with summer precipitation, a climate model of intermediate complexity (Neelin and Zeng 2000; Zeng et al. 2000, hereafter ZNC) is used. Based on the analytical solutions derived from the Betts-Miller moist convective adjustment scheme (Betts and Miller 1993), typical vertical structures of temperature, moisture, and winds for deep convection are used as leading basis functions for a Galerkin expansion (Neelin and Yu 1994; Yu and Neelin 1994). The resulting primitive equation model makes use of constraints on the flow by quasi-equilibrium thermodynamic closures and is referred to as QTCM1 
(a quasi-equilibrium tropical circulation model with a single vertical structure of temperature and moisture for deep convection). Because the basis functions are based on vertical structures associated with convective regions, these regions are expected to be well represented and similar to a GCM with the Betts-Miller moist convective adjustment scheme. Far from convective regions, QTCM1 is a highly truncated Galerkin representation equivalent to a two-layer model. A cloud-radiation scheme (Chou and Neelin 1996; ZNC), simplified from the full GCM radiation schemes (Harshvardhan et al. 1987; Fu and Liou 1993), is included. Deep convection and the cirrocumulus-cirrostratus cloud fraction are estimated by an empirical parameterization (Chou and Neelin 1999). A simple formula is used to obtain atmospheric boundary layer winds under the assumptions of a steady state and a vertically homogeneous mixed layer with fixed height (Stevens et al. 2002).

An intermediate land surface model with single layer for both energy and water budgets is used to simulate the interaction between the land surface and the atmosphere (Zeng et al. 2000). To examine air-sea interaction, a mixed-layer ocean with $50-\mathrm{m}$ fixed depth is coupled with the atmospheric model. The prescribed divergence of ocean heat transport, the $Q$ flux, in the mixed-layer ocean is estimated from a 10 -yr run with climatological SST.

\section{c. Experiment design}

To examine the mechanisms contributing to the Asian summer monsoon rainfall, several experiments were designed. First, a control run (the CTRL run) is forced by the prescribed seasonal SST. Second, a reduced run in which the longitudinal gradient of $F^{\text {net }}$ is reduced to the observed value by adding a cooling into the atmosphere above the Asian continent $\left(15^{\circ}-45^{\circ} \mathrm{N}\right.$ and $75^{\circ}-115^{\circ} \mathrm{E}$ ) and a heating above the neighboring ocean $\left(15^{\circ}-45^{\circ} \mathrm{N}\right.$ and $\left.115^{\circ}-175^{\circ} \mathrm{E}\right)$. To examine the $F^{\text {net }}$ impact on the precipitation in the second wet period, a pair of experiments forced by observed $F^{\text {net }}$ is also executed. In the $F^{\text {net }}$ run, the seasonal $F^{\text {net }}$ is prescribed globally in the MSE equation of QTCM. In the fixed $F^{\text {net }}$ run, the $F^{\text {net }}$ in the second wet period is replaced by the $F^{\text {net }}$ of the first wet period, so that $F^{\text {net }}$ repeats itself in the two wet periods. In these two experiments, the observed $F^{\text {net }}$ is the only forcing. Surface conditions, such as SST, land temperature, and soil moisture, do not affect the precipitation and the associated circulation. In other similar experiments, such as the evaporation ( $E$ run) and the longwave radiation (FLW run) experiments, only evaporation (or longwave radiation) is allowed to vary in these two wet periods, while other heat flux

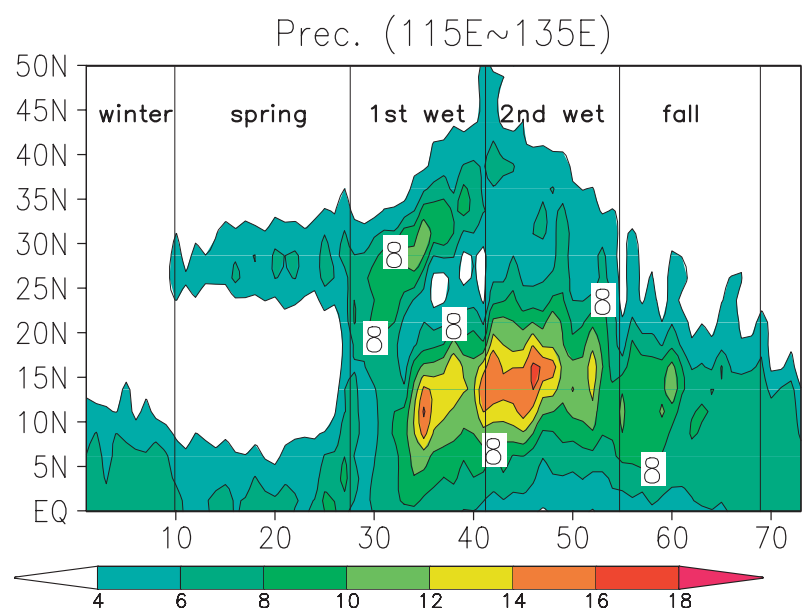

FIG. 1. The CMAP seasonal precipitation climatology $\left(\mathrm{mm} \mathrm{day}^{-1}\right)$ averaged over $115^{\circ}-135^{\circ} \mathrm{E}$ during the period of $1979-2006$. The abscissa unit is the pentad.

components are fixed. Thus, the impact of evaporation (or other heat fluxes) on the monsoon gyre can be examined. A mixed-layer ocean is also coupled with QTCM to examine atmosphere-ocean interaction. In this mixed run, an annual-mean $Q$ flux is used, so the seasonal variation of SST is only controlled by surface heat fluxes, not the $Q$ flux. All experiments shown here are 30-yr averages.

\section{Major precipitation periods over the WNP-EA sector}

\section{a. Major precipitation periods}

Figure 1 shows the annual cycle of the CMAP precipitation over the WNP-EA region $\left(115^{\circ}-135^{\circ} \mathrm{E}\right)$. The longitudinal average shows a clear picture of the evolution of the rainy system over the WNP-EA region, though it loses some detail in the longitudinal distribution, such as the eastward jump of the rainy system from the South China Sea to the Philippine Sea ( $\mathrm{Wu}$ and Wang 2001). The beginning of the year is first dominated by a dry season, which has the lowest rainfall from the 68th to the 9th pentad (Fig. 2b). Then, the onset of the spring precipitation system follows in midFebruary (the 10th pentad), ending around mid-May (the 27th pentad) before the onset of the summer monsoon system (Figs. 2a and 2b). Several high-frequency events associated with frontal systems (the $6 \mathrm{~mm}$ day $^{-1}$ contour) dominate the region between $25^{\circ}$ and $30^{\circ} \mathrm{N}$ in spring (Fig. 1). The precipitation averaged over $25^{\circ}-$ $30^{\circ} \mathrm{N}$ shows a jump occurring at the 10th pentad (Figs. 1 and $2 b$ ), which is associated with the onset of the spring rainy season. The jump between the 9 th and 10 th pentads 

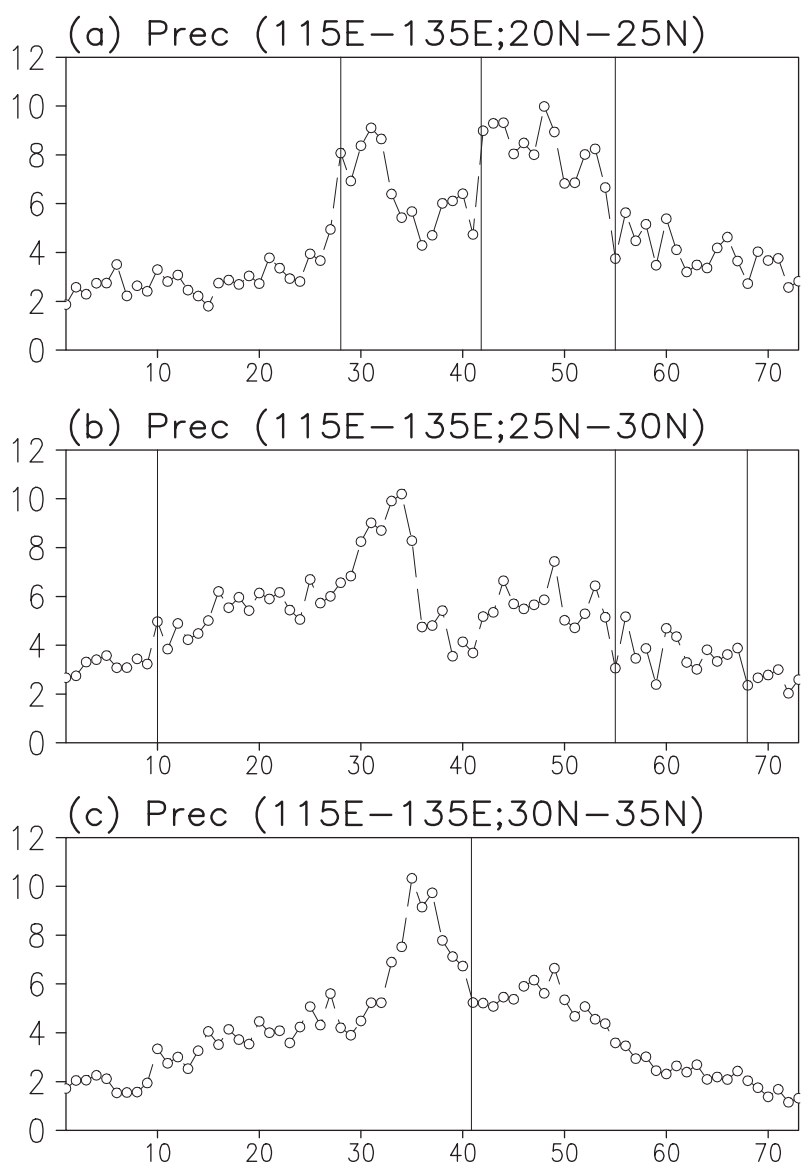

FIG. 2. The CMAP seasonal precipitation climatology ( $\mathrm{mm}$ day $^{-1}$ ) averaged over $115^{\circ}-135^{\circ} \mathrm{E}$ and (a) $20^{\circ}-25^{\circ} \mathrm{N}$, (b) $25^{\circ}-30^{\circ} \mathrm{N}$, and (c) $30^{\circ}-35^{\circ} \mathrm{N}$. The abscissa unit is the pentad.

in Fig. 2b is statistically significant at the 5\% level in the Wilcoxon-Mann-Whitney test (Chu 2002).

The major rainy season occurs in summer, which includes two main periods: the first from mid-May to late July (from the 28th to the 41st pentad), and the second from late July to late September (from the 42nd to the $54 \mathrm{rd}$ pentad), with abrupt increases in precipitation (between $20^{\circ}$ and $25^{\circ} \mathrm{N}$ ) at the 28th and 42 nd pentads (Fig. 2a). This is associated with the fast annual cycle proposed by LW02. The first rain peak in Fig. 2a is associated with the northward migration of rainy systems over the northern part of the WNP-EA region, while the second rain peak is associated with a northward jump of tropical convection (Fig. 1), with a dry break between these two rain peaks. During the first period, the rainfall maximum over the northern part of the WNP-EA region is associated with the pre-mei-yu/mei-yu frontal system, whereas the rainfall maximum over the southern part of the WNP-EA region is associated with the tropical convection system (LW02).
The pre-mei-yu/mei-yu frontal system starts around mid-May and moves northward from $20^{\circ}$ to $40^{\circ} \mathrm{N}$ as the season progresses. The frontal system ends around late July, shortly after the northward jump of the tropical convection. The tropical convection system between $5^{\circ}$ and $20^{\circ} \mathrm{N}$ starts somewhat late compared to the frontal system. The second period is dominated by the WNP summer monsoon gyre, which is an oceanic summer monsoon system (LW02). This monsoon gyre is associated with an abrupt northward jump of the WNP rainband from $20^{\circ} \mathrm{N}$ to north of $25^{\circ} \mathrm{N}$ sometime around late July; it ends around late September when cold and dry air starts to penetrate the WNP-EA region (Fig. 1). The mei-yu frontal system almost disappears in the second period (Figs. $2 \mathrm{~b}$ and $2 \mathrm{c}$ ).

When the cold dry air (the areas with precipitation less than $4 \mathrm{~mm} \mathrm{day}^{-1}$ in Figs. 1 and $2 \mathrm{~b}$ ) moves southward to around $20^{\circ} \mathrm{N}$ and the tropical convection retreats southward, the fall precipitation system starts to dominate this region. During this period, the southern part of the WNP-EA region (south of $20^{\circ} \mathrm{N}$ ) is still dominated by a tropical convection system with relatively weak amplitude, while the northern part of the region is dominated by frontal systems $\left(4 \mathrm{~mm}\right.$ day $^{-1}$ contour in Fig. 1). The region of the frontal precipitation is connected to tropical convection. This differs from the spring precipitation pattern in that the region of the spring frontal precipitation is disconnected from tropical convection. Using the $6 \mathrm{~mm} \mathrm{day}^{-1}$ contour as a rough definition for the convective margin, the tropical convection retreats from $20^{\circ} \mathrm{N}$ to south of $15^{\circ} \mathrm{N}$ as the season progresses (Fig. 1). Eventually, the WNP-EA region is completely dominated by the northerly winter monsoon flow-the onset of the winter season (Fig. 2b).

Based on the analysis from Figs. 1 and 2, five precipitation periods have been roughly identified, each with distinct characteristics. These five periods are spring (from the 10th to the 27th pentad), the first (from the 28th to the 41st pentad) and second (from the 42nd to the 54th pentad) wet periods, fall (from the 55th to the 67 th pentad), and winter (from the 68 th to the 9th pentad).

\section{b. Spatial patterns}

The spatial patterns of five precipitation periods over the WNP-EA region-winter, the first and second wet periods, spring, and fall-are shown in Fig. 3. The winter period (Fig. 3a) is a typical dry season over the WNPEA sector. Most precipitation occurs over the northern part of the WNP-EA region, east of Japan, far away from the Asian continent. Only a small local maximum in precipitation is found east of Taiwan. In this period, a 
(a) Winter (p68 p9)

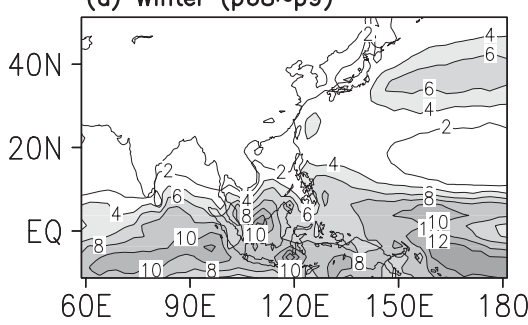

(c) 2nd wet (p42 p54)

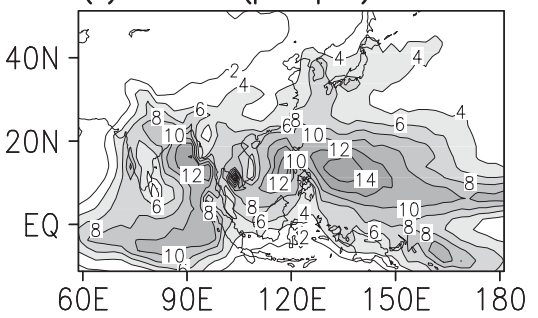

(e) Fall (p55 p67)

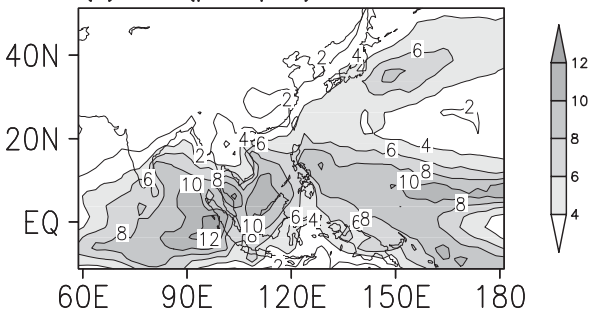

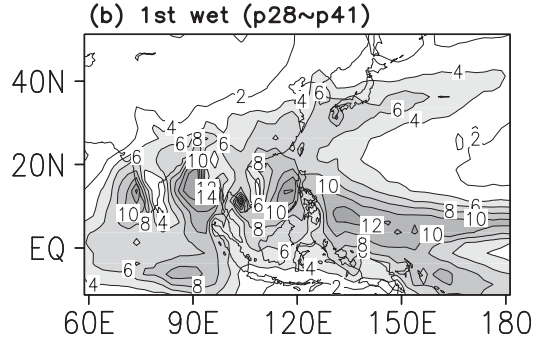

(d) Spring (p10 p27)

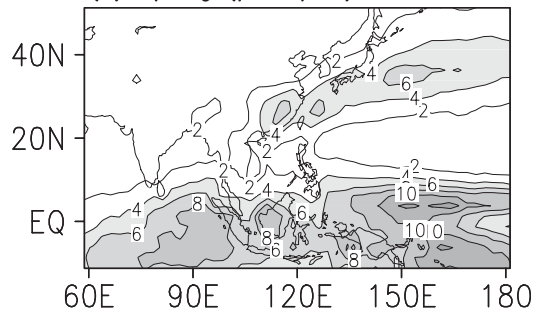

FIG. 3. The spatial distribution of the CMAP precipitation in the (a) winter, (b) first wet, (c) second wet, (d) spring, and (e) fall periods over the WNP-EA region. The contour interval is $2 \mathrm{~mm} \mathrm{day}^{-1}$.

continental high and the Aleutian low are clearly seen (Fig. 4a). The continental high extends southward into the South China Sea and the Philippines, while the Aleutian low is strengthened and deepened. A trough is found along the east coast of the Asian continent.

In the first wet period (Fig. 3b), the southwestnortheast-tilting pre-mei-yu/mei-yu rainband is along the east coast of the Asian continent from east of Japan to southeastern China, extending even farther southwest to Indochina and Indian peninsulas. This southwest-northeast-tilting rainband is associated with the northward movement of the precipitation maximum north of $25^{\circ} \mathrm{N}$ in the first wet period found in Fig. 1 . Besides the tilting rainband, four precipitation maxima are found in the following areas: the eastern Arabian Sea, the Bay of Bengal, the South China Sea, and the Philippine Sea. All four maxima are over ocean surfaces and are associated with the grand-onset pattern of the Asian summer monsoon (Hsu et al. 1999; LW02; Wang and $\mathrm{Xu} \mathrm{1997).} \mathrm{Only} \mathrm{the} \mathrm{last} \mathrm{two} \mathrm{are} \mathrm{within} \mathrm{our} \mathrm{area} \mathrm{of}$ interest. The first two rainfall maxima, located west of various mountains, are dominated by onshore south- westerly summer monsoon winds, leading to speculation that they might be induced by a wind-terrain interaction (Chang et al. 2005). The rainfall maximum over the South China Sea is associated with the South China Sea summer monsoon, while the maximum over the Philippine Sea is associated with the WNP summer monsoon (e.g., Chang and Chen 1995; Murakami and Matsumoto 1994; Ueda and Yasunari 1998; Wang and LinHo 2002; Wang et al. 2004; Wu and Wang 2000, 2001 and references therein). Both summer monsoons contribute to the heavy precipitation over the southern part of the WNP-EA region in the first wet period (Fig. 1). In the second wet period (Fig. 3c), the maximum precipitation over the Philippine Sea extends extensively northeastward and dominates the southern part of the WNP-EA region $\left(5^{\circ}-25^{\circ} \mathrm{N}\right.$ and $\left.120^{\circ}-160^{\circ} \mathrm{E}\right)$. This northeastward extension of the rainfall maximum is associated with the monsoon gyre over the WNP (LW02), which is a major feature of the mature phase of the WNP summer monsoon (Ueda et al. 1995; Ueda and Yasunari 1996). Other rainfall maxima occurring in the first wet period, such as those in the Bay of Bengal and 
(a) Winter $(p 68-p 9)$

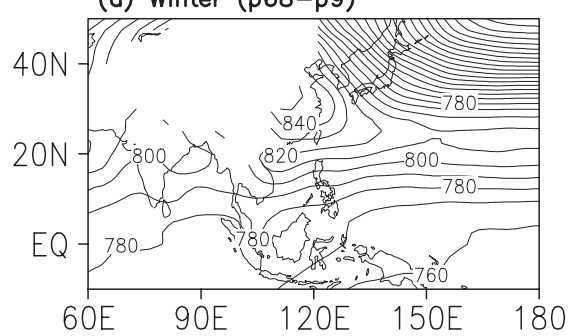

(c) 2nd wet (p42-p54)

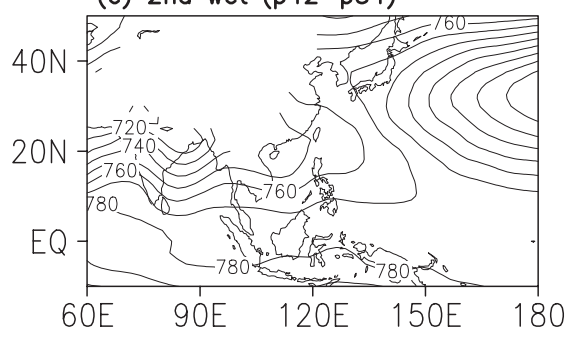

(e) Fall (p55-p67)

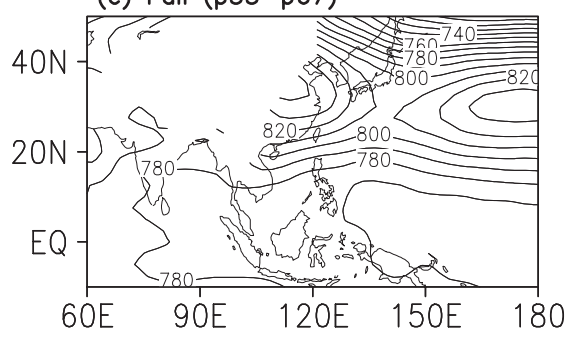

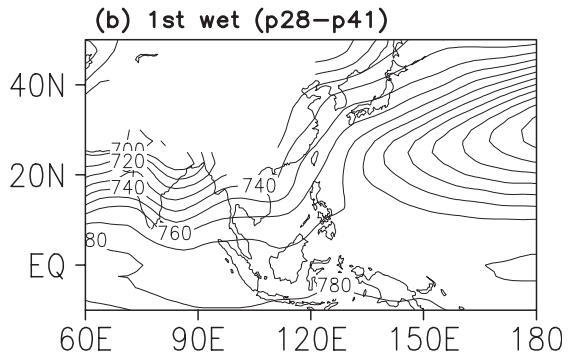

(d) Spring (p10-p27)

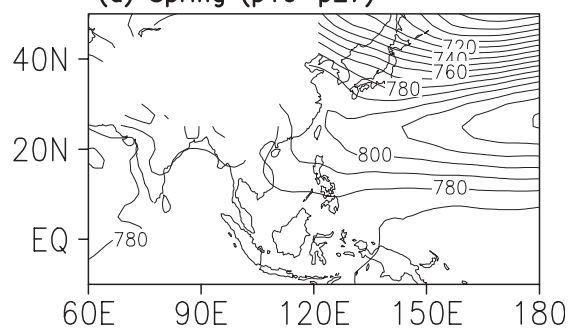

FIG. 4. As in Fig. 3 but for observed 925-hPa geopotential height. The contour interval is $10 \mathrm{~m}$. The area of the Tibetan Plateau has been masked out.

the South China Sea, still exist. In contrast, the southwestnortheast-tilting mei-yu rainband almost disappears in this period.

In the boreal summer, the patterns of geopotential height are completely reversed compared to the boreal winter pattern. A low-level cyclonic circulation over the Asian continent persists through the two summer precipitation periods, but the circulation patterns over the WNP-EA region are very different between the first and second wet periods. During the first wet period, the Pacific subtropical high reaches to the Philippine Sea, while the monsoon trough extends only to the South China Sea (Fig. 4b). In the second wet period, the monsoon trough deepens into the southern part of the WNP, including the Philippine Sea, and the Pacific subtropical high is shifted northward toward Japan and Korea (Fig. 4c). In other words, the Pacific subtropical high retreats eastward over the southern part of the WNP-EA region, but not over the northern part. This strengthened monsoon trough creates favorable conditions for generating tropical cyclones, so the second wet period is also called the typhoon season in this region
(LW02). This seasonal/subseasonal variation of the monsoon trough and the Pacific subtropical high has also been discussed in several studies (e.g., LW02; Wu 2002; Wu and Wang 2001).

Between the wet and dry seasons, two transition phases are associated with the spring and fall periods. The spring precipitation pattern (Fig. 3d) has a southwestnortheast-tilting rainband that extends from the northern part of the WNP (east of Japan) to southeast China. The spring rainband extends southward to around $20^{\circ}-25^{\circ} \mathrm{N}$, consistent with the spring precipitation found in Figs. 1 and 2. A dry region around $15^{\circ} \mathrm{N}$ separates the spring rainband and the tropical convection zones, implying that the spring precipitation system is independent of the tropical convection. The fall precipitation pattern (Fig. $3 \mathrm{e})$ also has a southwest-northeast tilting rain band over the northern part of the WNP-EA region (east of Japan). Over the southern part of the WNP-EA region (south of $20^{\circ} \mathrm{N}$ ), tropical convection dominates, but its amplitude is weaker than that in the wet season. No clear dry region is found between the tilting rainband and the tropical convection during this period. 
In the spring period (Fig. 4d), the continental high over central Asia is not only weakened, but also retreats more northward compared to its position during the winter period. The Pacific subtropical high extends westward to the South China Sea and the Indochina peninsula, which is consistent with the dry region around $15^{\circ} \mathrm{N}$ shown in Fig. 3d. In the fall period (Fig. $4 \mathrm{e})$, the geopotential height pattern is similar to that of the winter period. The continental high in the fall period does not extend as much southward as it does in the winter period. In the fall period, the Pacific subtropical high retreats more eastward compared to its position in the spring period. A trough is found over Japan, which is consistent with the fall rainfall associated with the frontal systems shown in Fig. 3e.

\section{The wet phase}

\section{a. The moisture and moist static energy budgets}

The WNP-EA region in summer is dominated by the Asian summer monsoon circulation. Two distinct precipitation periods discussed in the previous section are associated with the fast annual cycle of the Asian-Pacific summer monsoon (LW02). Here, we would like to examine some of the possible processes that are associated with precipitation in these two periods. The vertically integrated moisture equation is used first:

$$
\partial_{t}\langle q\rangle+\langle\mathbf{v} \cdot \nabla q\rangle+\left\langle\omega \partial_{p} q\right\rangle=E-P
$$

or in flux form

$$
\partial_{t}\langle q\rangle+\langle\nabla \cdot \mathbf{v} q\rangle=E-P,
$$

using $\omega=0$ at the top and bottom of the vertical integral. In the equations above, $E$ is evaporation, $P$ is precipitation, $\omega$ is pressure velocity, and $\mathbf{v}$ is horizontal velocity. The vertical integral over the troposphere with $p_{T}$ as the depth of the troposphere \langle\rangle is written as

$$
\langle X\rangle=\frac{1}{g} \int_{p_{T}} X d p,
$$

where $g$ is gravity. The specific humidity $q$ is in energy units and determined by absorbing the latent heat per unit mass, $L$. Considering a steady state, precipitation can then be estimated by

$$
\begin{aligned}
P & \approx-\left\langle\omega \partial_{p} q\right\rangle-\langle\mathbf{v} \cdot \nabla q\rangle+E \\
& \approx-\langle\nabla \cdot \mathbf{v} q\rangle+E .
\end{aligned}
$$

Precipitation is balanced by vertical moisture advection, horizontal moisture advection, and evaporation. In the flux form, on the other hand, precipitation is balanced by the divergence of the moisture flux, $-\langle\nabla \cdot \mathbf{v} q\rangle$, and evaporation. In other words, the divergence of the moisture flux is contributed to by the term associated with the vertical moisture advection, $-\left\langle\omega \partial_{p} q\right\rangle$, and the term associated with the horizontal moisture advection, $-\langle\mathbf{v} \cdot \nabla q\rangle$.

The term $-\left\langle\omega \partial_{p} q\right\rangle$ is an atmospheric dynamic feedback that is associated with convection in the WNP-EA summer season. Thus, the associated rising motion can be estimated from the vertically integrated moisture static energy (MSE) equation in a steady state:

$$
\left\langle\omega \partial_{p} h\right\rangle \approx-\langle\mathbf{v} \cdot \nabla(T+q)\rangle+F^{\text {net }},
$$

where the moist static energy is $h=s+q$, with $s$ being the dry static energy. The temperature $T$ is also in an energy unit and derived by absorbing the specific heat at constant pressure, $C_{p}$. The net heat flux into the atmospheric column is given by

$$
F^{\text {net }}=F_{t}+F_{s},
$$

where the net heat flux at the top of the atmosphere (TOA) can be obtained by

$$
F_{t}=S_{t}^{\downarrow}-S_{t}^{\uparrow}-R_{t}^{\uparrow}
$$

and the net heat flux at the surface is from

$$
F_{s}=S_{s}^{\uparrow}-S_{s}^{\downarrow}-R_{s}^{\downarrow}+R_{s}^{\uparrow}+E+H .
$$

Subscripts $s$ and $t$ on the solar $\left(S^{\downarrow}\right.$ and $\left.S^{\uparrow}\right)$ and longwave $\left(R^{\uparrow}\right.$ and $R^{\downarrow}$ ) radiative terms denote the surface and TOA, and $R_{t}^{\downarrow} \approx 0$ has been used. Here, $H$ is sensible heat flux. Positive values of $F_{t}$ and $F_{s}$ indicate heat fluxes into the atmosphere column.

In (6), $\left\langle\omega \partial_{p} h\right\rangle$ is roughly proportional to the rising motion associated with convection (e.g., Yu and Neelin 1997). Based on (6), the convergence of the columnintegrated MSE, $-\left\langle\omega \partial_{p} h\right\rangle-\langle\mathbf{v} \cdot \nabla(T+q)\rangle$, must be balanced by the net heat flux into the atmospheric column, $F^{\text {net }}$ (Chou et al. 2001; Chou and Neelin 2003). This balance, which has been used to determine the gross moist stability of the troposphere (Neelin and Held 1987; Neelin and Yu 1994; Zeng and Neelin (1999), also shows how $F^{\text {net }}$ can drive moisture convergence in convective regions over land.

\section{b. The first wet period}

Figure 5 shows the observed moisture and MSE budgets in the first wet period. In Fig. 5a, the westerly winds from south Asia and the easterly trade winds from the Pacific Ocean converge near the Philippine and South 

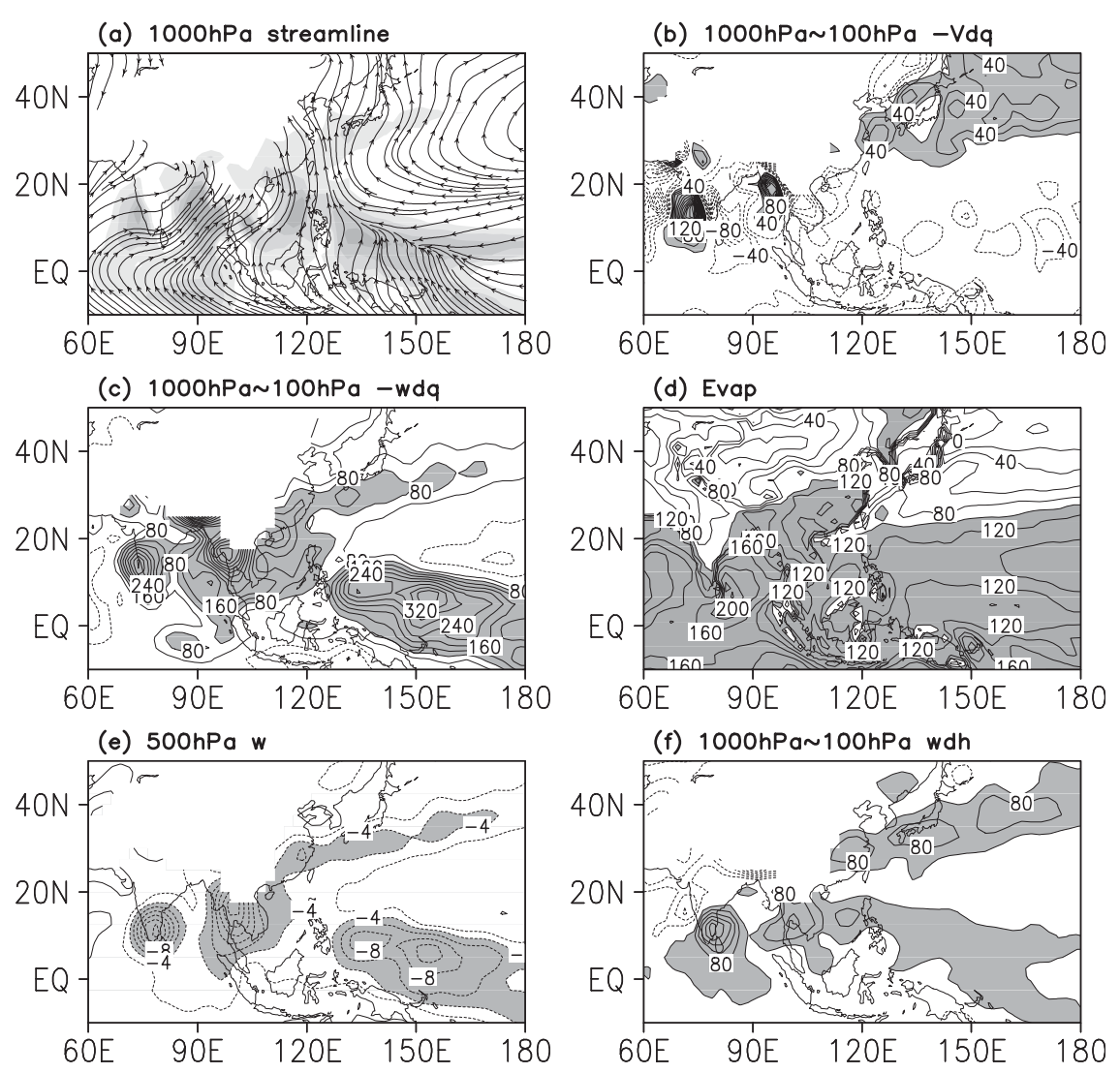

(g) Fnet
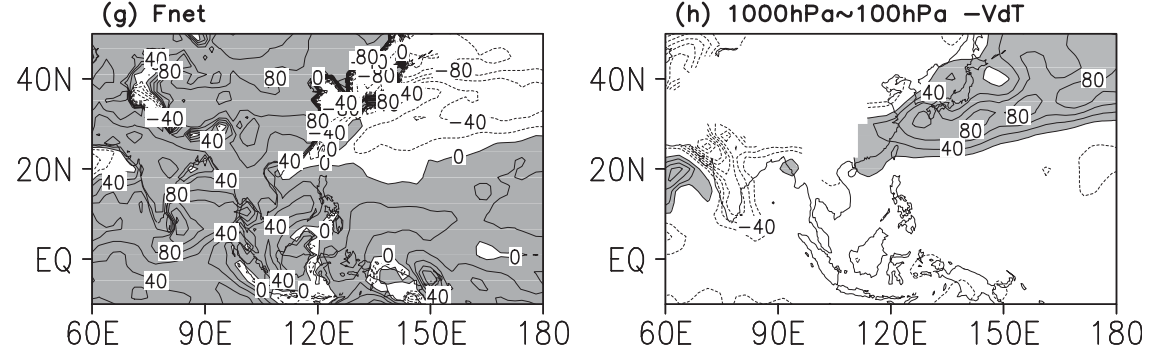

FIG. 5. Spatial distributions of observations in the first wet period for the (a) 1000-hPa streamline shaded with the precipitation over $6 \mathrm{~mm} \mathrm{day}^{-1},(\mathrm{~b})-\mathbf{v} \cdot \nabla q$ integrated over 1000 $100 \mathrm{hPa},(\mathrm{c})-\omega \partial_{p} q$ integrated over 1000-100 hPa, (d) evaporation, (e) pressure velocity at $500 \mathrm{hPa}\left(10^{-2} \mathrm{~Pa} \mathrm{~s}^{-1}\right)$, (f) $\omega \partial_{p} h$ integrated over $1000-100 \mathrm{hPa},(\mathrm{g}) F^{\text {net }}$, and (h) $-\mathbf{v} \cdot \nabla T$ integrated over $1000-100 \mathrm{hPa}$. The contour interval is $20 \mathrm{~W} \mathrm{~m}^{-2}$ for $(\mathrm{b}),(\mathrm{d}),(\mathrm{g})$, and (h), and $40 \mathrm{~W} \mathrm{~m}^{-2}$ for (c) and (f).

China Seas before turning north along the east coast of the Asian continent. Cross-equatorial flow from the Maritime Continent also merges into the region. Analyzing the moisture budget in the first wet period, the rainfall pattern is very similar to the convergence of the moisture flux $-\langle\nabla \cdot \mathbf{v} q\rangle$ (positive values in Figs. 5b and $5 \mathrm{c}$ ), while the corresponding evaporation exhibits a broad and smooth spatial distribution (Fig. 5d). In the convergence of the moisture flux, the vertical moisture advection $-\left\langle\omega \partial_{p} q\right\rangle$ is much more dominant than the horizontal moisture advection $-\langle\mathbf{v} \cdot \nabla q\rangle$, which only contributes to a part of the rainfall west of the Indian Peninsula, the Bay of Bengal, and East Asia from the East China Sea to east of Japan. The strong horizontal moisture advection west of the Indian Peninsula and the Bay of Bengal is due to the onshore southwesterly monsoon flow interacting with the terrain (Chang et al. 2005).

The term $-\left\langle\omega \partial_{p} q\right\rangle$ is a dynamical feedback associated with vertical motion shown in Fig. 5e. To estimate the corresponding vertical velocity, the observed MSE budget is diagnosed since convection is a dominant 

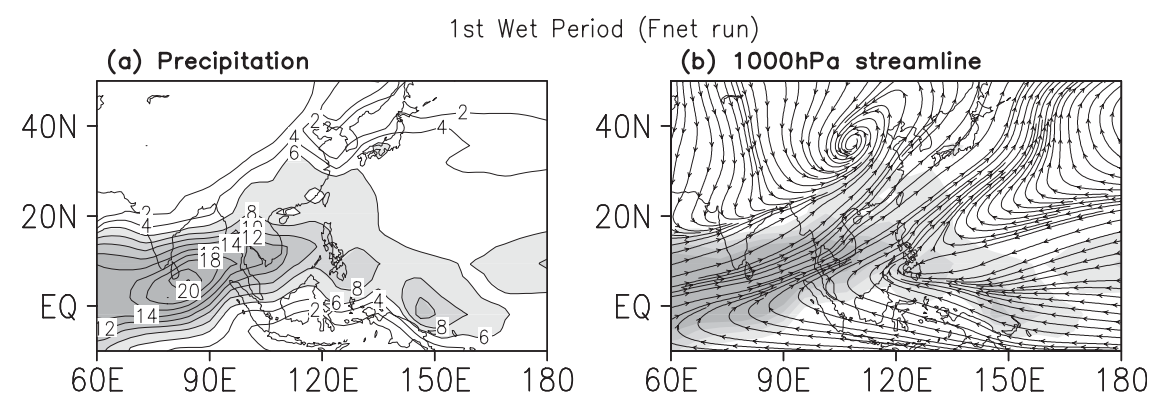

FIG. 6. Spatial distributions of the $F^{\text {net }}$ run in the first wet period for (a) precipitation and (b) the $1000-\mathrm{hPa}$ streamline shaded with the precipitation over $6 \mathrm{~mm} \mathrm{day}^{-1}$.

process for inducing vertical velocity. The term associated with vertical velocity in the MSE budget is $\left\langle\omega \partial_{p} h\right\rangle$ (Fig. 5f), which is balanced by the net energy into the atmosphere, $F^{\text {net }}$ (Fig. 5g), and horizontal MSE advection, $-\langle\mathbf{v} \cdot \nabla(T+q)\rangle$ (Figs. 5b and $5 \mathrm{~h}$ ). Only positive numbers of $F^{\text {net }}$ and $-\langle\mathbf{v} \cdot \nabla(T+q)\rangle$ can induce ascending motion. Thus, the ascent of the tilting rainband northeastward from southeastern China to east of Japan (Fig. 5e) is mainly associated with both horizontal moisture and temperature advections (Figs. 5b and 5h). The ascent over the South China Sea and the Philippine Sea (Fig. 5e), on the other hand, is associated with positive $F^{\text {net }}$.

The land-sea thermal contrast is thought to be fundamental to summer monsoon circulations (Webster 1987; Young 1987). Over land, the net surface heat flux $F_{s}$ is near zero (Zeng and Neelin 1999), so $F^{\text {net }}$ is determined by $F_{t}$, which is positive due to strong solar radiation. Over the ocean, $F_{s}$ is balanced by ocean heat storage and transport, which is not near zero, so there is a land-ocean contrast in $F^{\text {net }}$. Previous studies (e.g., Chou et al. 2001; Chou and Neelin 2003; Neelin 2007) indicate that $F^{\text {net }}$ is a leading cause of the land-ocean contrast for summer monsoons, not surface temperature. Thus, an experiment with QTCM forced by the prescribed $F^{\text {net }}$ shown in Fig. $5 \mathrm{~g}$ is performed (the $F^{\text {net }}$ run) to examine the effect of the land-sea $F^{\text {net }}$ contrast. In this experiment, no seasonal variation, such as solar insolation, is allowed, except $F^{\text {net }}$. Figure 6 shows the result in which similar Asian summer monsoon rainfall and circulation patterns are created. We note that the rainfall associated with the mei-yu front is relatively weak, which may be due to weak horizontal moisture convergence forced by the $F^{\text {net }}$-only forcing. Overall, the land-ocean contrast of $F^{\text {net }}$ can roughly induce the Asian summer monsoon circulation and the associated rainfall, particularly the rainfall over the southern part of the WNP-EA region, even when the atmosphere does not feel the differences in the surface temperature between land and ocean.
The southwest-northeast-tilting pre-mei-yu/mei-yu rainband is a part of the typical rainfall pattern associated with the summer monsoon circulation, which extends farther southwestward to northern tropical Africa (Chou et al. 2001; Liu and Yanai 2001). Strong solar heating creates positive $F^{\text {net }}$ over the continental region (Fig. 5g), which induces a continental low and the associated cyclonic summer monsoon circulation at a lower troposphere (Fig. 5a). The strong dry and cold advection over the Asian continent (Figs. 5b and 5h) associated with a ventilation effect induces the eastwest asymmetry of the precipitation. In this ventilation mechanism, the dry and low moist static energy air imported by cross-continental flow suppresses convection over the western part of the Asian continent. In an experiment with suppressed horizontal moisture and temperature advection (not shown), the heavy rainy area does extend much more northward and more inland over the Asian continent than in the control experiment. Meanwhile, the northeast-southwest-tilting rainband along the east coast of the Asian continent is reduced significantly, which is further evidence that the tilting rainband is associated with $-\langle\mathbf{v} \cdot \nabla(T+q)\rangle$. Another mechanism, the interactive Rodwell-Hoskins mechanism (Rodwell and Hoskins 1996, 2001), is also partially responsible for this east-west asymmetry of the precipitation (Chou et al. 2001). In the interactive Rodwell-Hoskins mechanism, the monsoon convective heating over the eastern part of the Asian continent induces a Rossby wave subsidence to its west that further reduces the precipitation over the western part of the Asian continent. A detailed discussion regarding this asymmetry of the Asian summer monsoon rainband can be found in Chou and Neelin (2003).

We next examine possible processes that maybe associated with the onset of the first wet period. Since the land-ocean contrast of $F^{\text {net }}$ is an important forcing that induces the Asian summer monsoon, the variation of $F^{\text {net }}$ between the Asian continent and the North Pacific Ocean is examined (Fig. 7). In the boreal summer, 


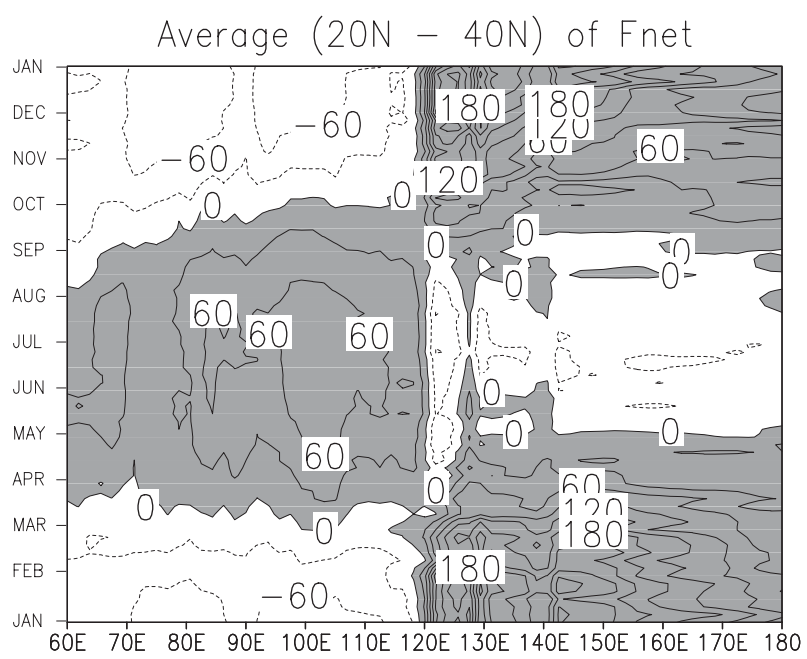

FIG. 7. The annual variation of $F^{\text {net }}$ averaged over $20^{\circ}-40^{\circ} \mathrm{N}$. The contour interval is $30 \mathrm{~W} \mathrm{~m}^{-2}$ with shading for positive values.

positive $F^{\text {net }}$ is found over land, and negative $F^{\text {net }}$ is found over ocean. In the boreal winter, on the other hand, the signs of $F^{\text {net }}$ are reversed. This reversal occurs in early May, around the onset of the first wet period, implying that the land-ocean contrast of $F^{\text {net }}$ may be associated with the onset of the first wet period. However, the exact onset time of the first wet period in each year may be related to an intraseasonal variation $(\mathrm{Wu}$ and Wang 2000). As the season progresses, the landocean contrast of $F^{\text {net }}$ enhances, so the tilting rainband moves northward (Fig. 1).

Overall, in a steady state, the rainfall over the Philippine and South China Seas is associated with the moisture convergence $-\left\langle\omega \partial_{p} q\right\rangle$ that is mainly induced by positive $F^{\text {net }}$. On the other hand, the rainfall of the southwest-northeast-tilting pre-mei-yu/mei-yu rainband is associated with the moisture convergence $-\left\langle\omega \partial_{p} q\right\rangle$ that is induced by $-\langle\mathbf{v} \cdot \nabla(T+q)\rangle$. Over the Asian continent, positive $F^{\text {net }}$ is canceled by strong cold and dry advection, which has been termed the "ventilation effect" (Chou et al. 2001); thus, no rain occurs over most of the Asian continent even though $F^{\text {net }}$ is positive over the entire continent.

\section{c. The second wet period}

Similar to the previous section regarding the first wet period, we first examine the observed moisture and MSE budgets (Fig. 8). The summer monsoon trough extends eastward from the South China Sea into the WNP where it is associated with strong precipitation (Fig. 8a). The Pacific subtropical high shifts northward to Korea and Japan. Similar to the first wet period, the convergence of moisture flux, $-\langle\nabla \cdot \mathbf{v} q\rangle$ (positive values in Figs. $8 \mathrm{~b}$ and $8 \mathrm{c}$ ), dominates the rainfall of the second wet period. Stronger positive evaporation moves farther northward in the second than in the first wet period (Figs. 5d and 8d). In the convergence of moisture flux, the vertical moisture advection $-\left\langle\omega \partial_{p} q\right\rangle$ is the most important factor in supplying moisture in the second wet period, as it is in the first wet period. The horizontal moisture advection, on the other hand, becomes weaker in the second than in the first wet period. The term $-\left\langle\omega \partial_{p} q\right\rangle$ is associated with vertical velocity (Figs. $8 \mathrm{c}$ and 8e), which can be estimated via $\left\langle\omega \partial_{p} h\right\rangle$ (Fig. 8f) in the MSE budget. In the MSE budget, $\left\langle\omega \partial_{p} h\right\rangle$ is balanced by $F^{\text {net }}($ Fig. $8 \mathrm{~g})$ and $-\langle\mathbf{v} \cdot \nabla(T+q)\rangle$ (Figs. 8b and 8h). Both the positive moisture and temperature advections are much weaker and occur only over the east of Japan, so $F^{\text {net }}$ becomes the most dominant factor for inducing the ascent over the WNP-EA region.

Figures $8 \mathrm{e}-\mathrm{g}$ show that the spatial distributions of $F^{\text {net }}$ and the ascent are very different. Is $F^{\text {net }}$ really responsible for inducing rainfall in the second wet period, particularly that over the South China Sea and the western North Pacific? To examine the impact of $F^{\text {net }}$, the $F^{\text {net }}$ run, which is forced by the prescribed $F^{\text {net }}$ shown in Fig. 8g, is conducted. The result also shows that QTCM can roughly simulate similar Asian summer monsoon circulation and rainfall patterns, particularly the eastward extension of the summer monsoon trough (Fig. 9), which is the main difference between these two periods. This indicates that $F^{\text {net }}$ plays an important role in inducing rainfall in the second wet period, and the difference in $F^{\text {net }}$ between the first and second wet periods is responsible for the deepening of the monsoon trough. We note that the simulated rainfall maximum over the WNP is a little more southward than in the observations (Fig. 8a) and the associated monsoon trough does not extend as far eastward as is shown in Fig. 8a. These resultscould be due to the limitations of QTCM.

To more precisely identify the location of the WNP summer monsoon gyre, the differences in the observations between the second and the first wet periods are examined first. A clear WNP summer monsoon gyre rainband is located over the region of $10^{\circ}-25^{\circ} \mathrm{N}$ and $120^{\circ}-170^{\circ} \mathrm{E}$ (Fig. 10a). Note that Taiwan is located just over the northwestern margin of this major rainy area. To its north and south, negative precipitation differences are found. The precipitation differences along the east coast of the Asian continent form a well-known sandwich pattern that is also often found in an interannual variation (Chou et al. 2003; Hsu and Liu 2003; Hsu and Lin 2007; Lau and Wu 2001; Wang et al. 2001). The WNP summer monsoon gyre rainfall maximum is associated with an elongated low-level cyclonic circulation between $10^{\circ}$ and $30^{\circ} \mathrm{N}$ (Fig. 10b), which is consistent 
(a) $1000 \mathrm{hPa}$ streamline

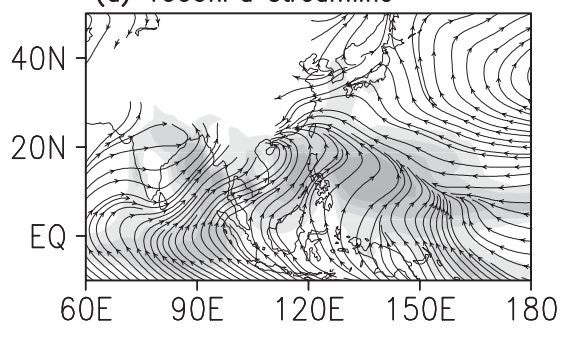

(c) $1000 \mathrm{hPa} 100 \mathrm{hPa}-\mathrm{wda}$

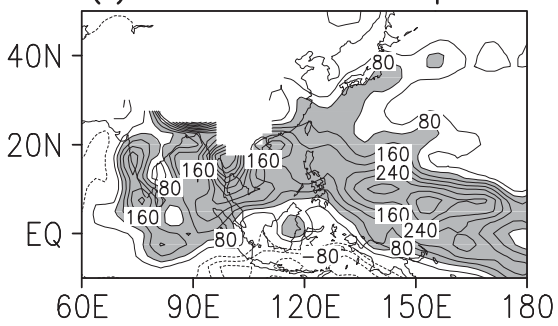

(e) $500 \mathrm{hPa} \mathrm{w}$

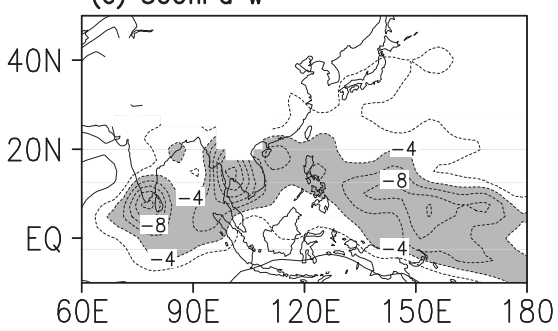

(g) Fnet

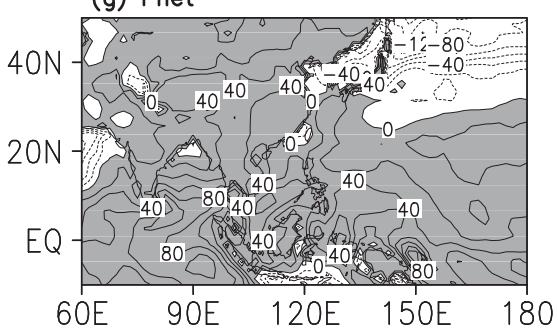

(b) $1000 \mathrm{hPa} 100 \mathrm{hPa}-\mathrm{Vda}$

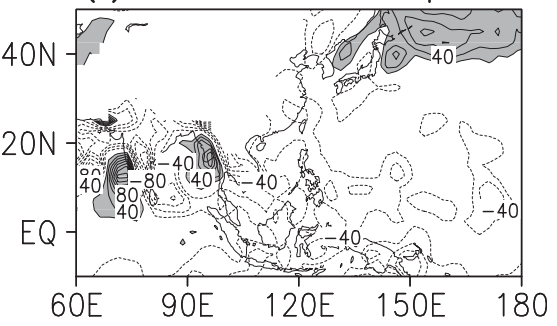

(d) Evap

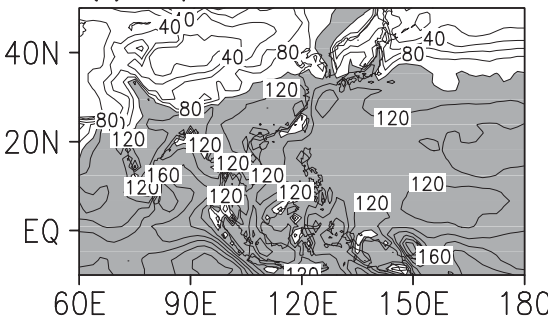

(f) $1000 \mathrm{hPa} 100 \mathrm{hPa}$ wdh

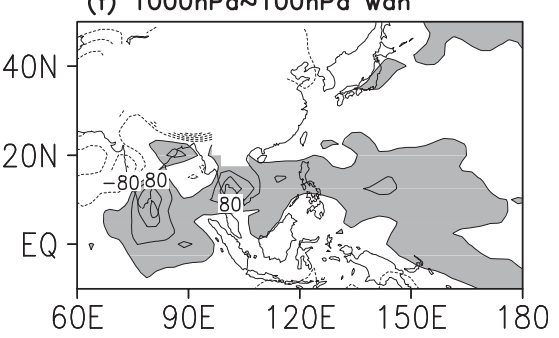

(h) $1000 \mathrm{hPa} 100 \mathrm{hPa}-\mathrm{VdT}$

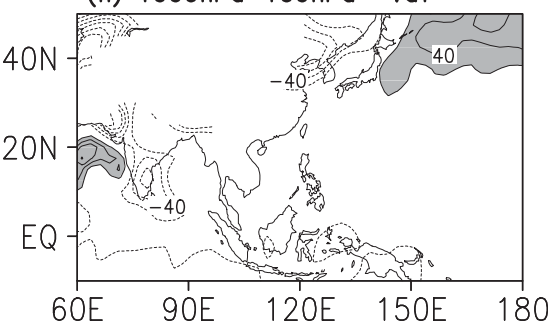

FIG. 8. As in Fig. 5 but for the second wet period.

with the eastward extension of the Asian summer monsoon trough.

A further examination of the observed SST difference between the second and the first wet periods reveals that warmer SSTs extend much farther northeastward in the second wet period even though solar radiation has already reached its maximum in the first wet period. The area with warmer SSTs and temperatures higher than (a) Precipitation

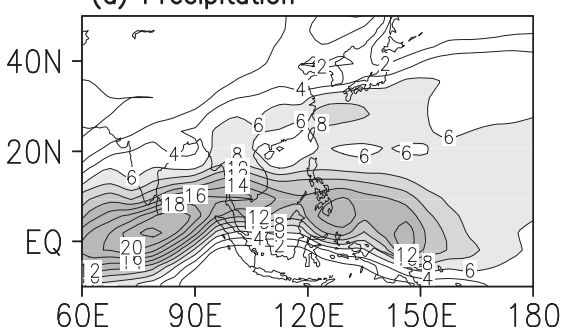

2nd Wet Period (Fnet run)

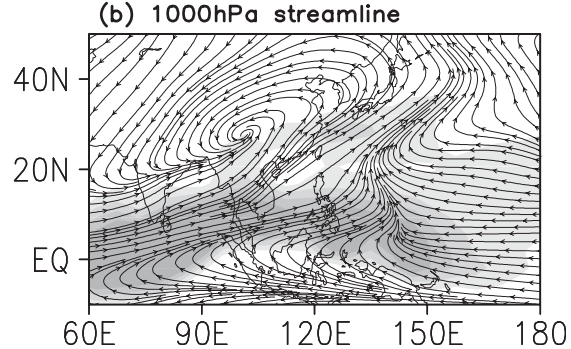

FIG. 9. As in Fig. 6 but for the second wet period. 
(a) 2nd-1st Precip.

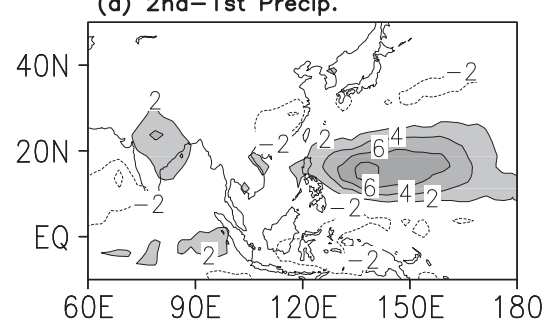

(c) 2 nd-1st SST

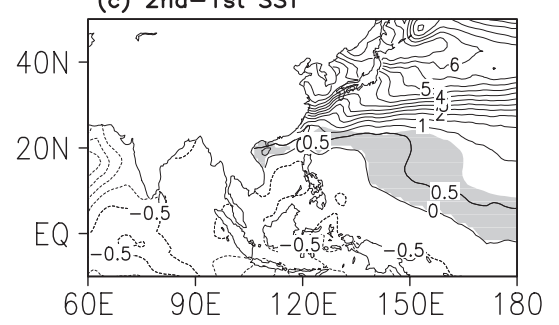

(e) 2nd-1st Prec (Fnet run)

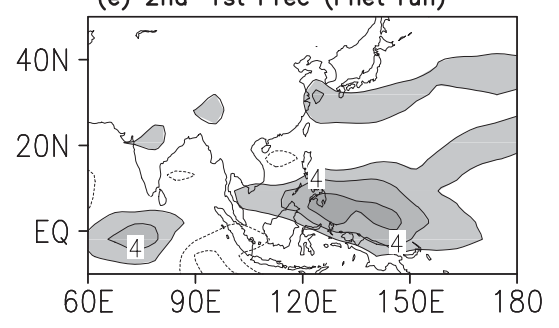

(b) 2 nd-1st $1000 \mathrm{hPa}$ streamline

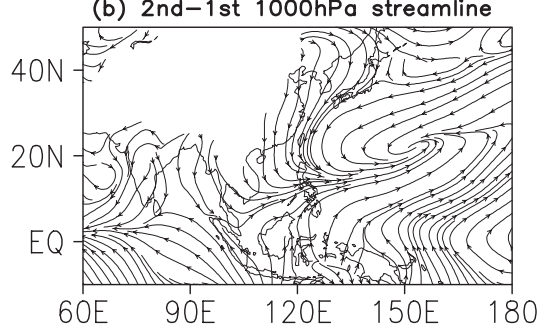

(d) 2nd-1 st Fnet

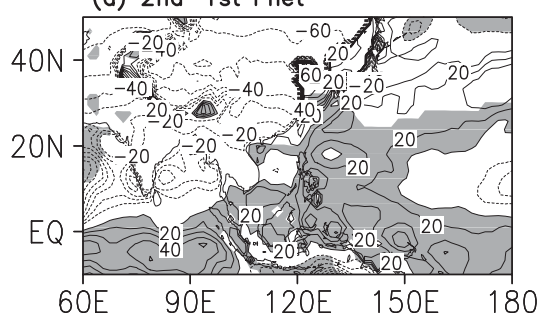

(f) $2 \mathrm{nd}-1$ st $1000 \mathrm{hPa}$ stream (Fnet run)

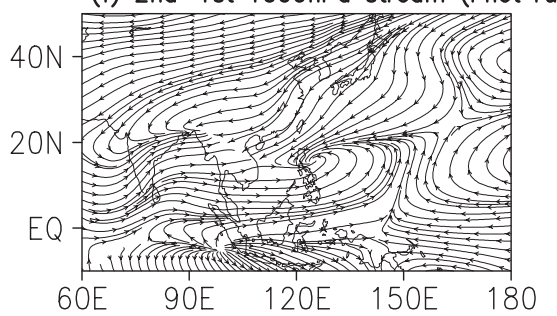

FIG. 10. Differences between the second minus first wet periods for the observed (a) precipitation with a $2 \mathrm{~mm}_{\text {day }}{ }^{-1}$ interval, (b) 1000-hPa streamline, (c) SST (with $1^{\circ} \mathrm{C}$ interval above $1^{\circ} \mathrm{C}$ ), (d) $F^{\text {net }}$ (with a $20 \mathrm{~W} \mathrm{~m}^{-2}$ interval). (e),(f) As in (a),(b) but for the $F^{\text {net }}$ run. The shading in (c) is for the area with the SSTs in the second wet period that are warmer than the first wet period and higher than $29^{\circ} \mathrm{C}$. The shading in (d) is for the area with the $F^{\text {net }}$ difference larger than $10 \mathrm{~W} \mathrm{~m}^{-2}$ and for the area of the positive $F^{\text {net }}$ in the second wet period.

$29^{\circ} \mathrm{C}$ in the second wet period (shaded in Fig. 10c) roughly coincides with the summer monsoon gyre. This implies that the warmer SSTs could be responsible for inducing the summer monsoon gyre. The choice of $29^{\circ} \mathrm{C}$ is attributed to the findings of previous studies (Sobel and Bretherton 2000; Masunaga et al. 2005), which imply that this temperature is a critical value for deep convection over this region. The corresponding positive $F^{\text {net }}$ in the second wet period that is larger than that in the first wet period also coincides well with the summer monsoon gyre rainfall. Thus, the increased $F^{\text {net }}$, which is associated with the warmer SST, may induce the summer monsoon gyre rainfall. However, the association of SST with the establishment of the summer monsoon gyre could be more complicated (Wu 2002; Wu and Wang 2001). Comparing the evolution of the precipitation and $F^{\text {net }}$ over the WNP $\left(10^{\circ}-25^{\circ} \mathrm{N}\right)$, the precipitation larger than $10 \mathrm{~mm}$ day ${ }^{-1}$ is consistent with $F^{\text {net }}$ larger than $40 \mathrm{Wm}^{-2}$ (Figs. 11a and 11b). This is further evidence that the summer monsoon gyre in the second wet period is associated with stronger $F^{\text {net }}$.
The SST over the Northern Hemisphere starts to warm when the sun moves from the Southern to the Northern Hemisphere. It increases beyond $29^{\circ} \mathrm{C}$ first over the Bay of Bengal (around $100^{\circ} \mathrm{E}$ ) and the eastern Arabian Sea (around $75^{\circ} \mathrm{E}$ ), then over the South China Sea (Fig. 11c). The SST over the WNP becomes warmer than $29^{\circ} \mathrm{C}$ around late July when the WNP summer monsoon gyre is developed. This is consistent with the 1.5-2-month lag of the WNP summer monsoon gyre development (around late July), as compared to the South China Sea summer monsoon onset (around mid May). We note that the ocean surface does not occupy the entire domain of $10^{\circ}-30^{\circ} \mathrm{N}$ over these areas, such as in the WNP. The delayed responses of the maximum SST over the WNP could be caused by a weakening of easterly winds around $20^{\circ} \mathrm{N}$ and $150^{\circ}-160^{\circ} \mathrm{E}$ (Ueda and Yasunari 1996). Cloud radiation may also play a role in a complicated air-sea interactive process (Wu 2002). Another possible reason for the lag in the SST over the WNP is the differences in the depth of the ocean mixed layer. According to the estimation of Kara et al. (2003), 


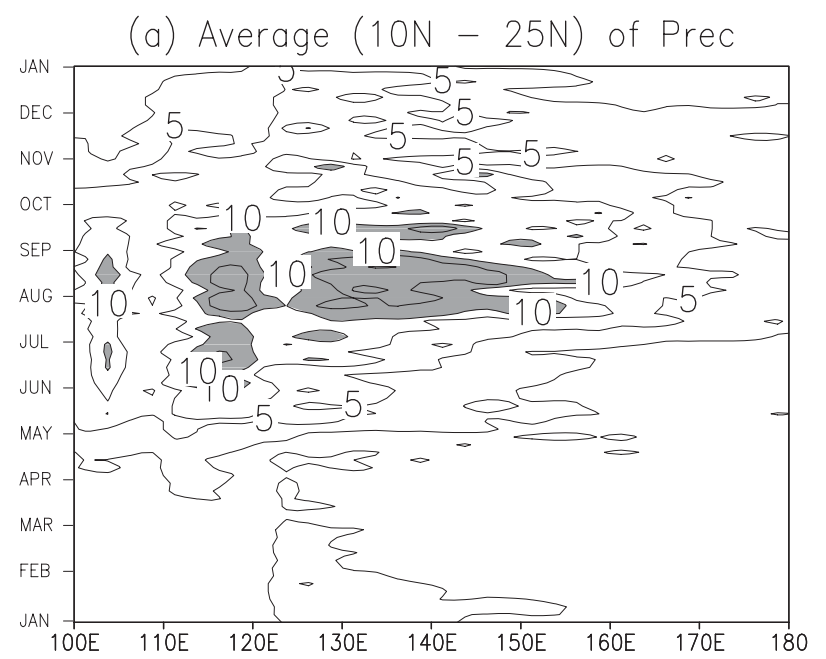

(b) Average $(10 N-25 N)$ of Fnet

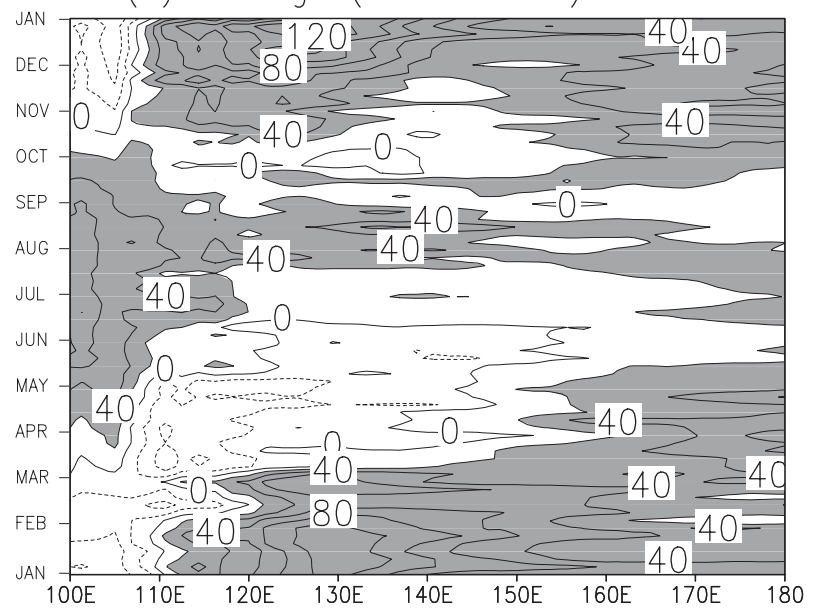

(c) Average $(10 \mathrm{~N}-30 \mathrm{~N})$ of SST

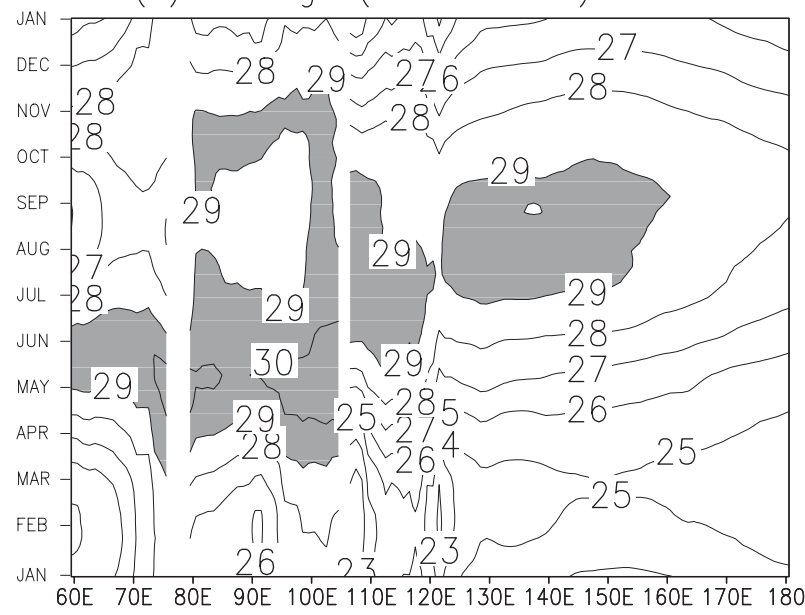

FIG. 11. The annual variation of (a) precipitation averaged over $10^{\circ}-25^{\circ} \mathrm{N}$, (b) $F^{\text {net }}$ averaged over $10^{\circ}-25^{\circ} \mathrm{N}$, and (c) SSTs averaged over $10^{\circ}-30^{\circ} \mathrm{N}$. The contour interval is $2.5 \mathrm{~mm}$ day $^{-1}$ with shading for precipitation above $10 \mathrm{~mm} \mathrm{day}^{-1}$ in (a), $20 \mathrm{~W} \mathrm{~m}^{-2}$ with shading for $F^{\text {net }}$ above $20 \mathrm{~W} \mathrm{~m}^{-2}$ in (b), and $1^{\circ} \mathrm{C}$ with shading for temperature above $29^{\circ} \mathrm{C}$ in (c). the eastern Arabian Sea and the Bay of Bengal have the shallowest mixed-layer depths, the Philippine Sea and the southern part of the WNP have the deepest mixedlayer depths, and the South China Sea is in between. Due to this difference in mixed-layer depths between the Indian Ocean, the South China Sea, and the southern part of the WNP, the warming of SST over the WNP with the deepest mixed-layer depth should be slower than the SST warming over the South China Sea. To better understand the effects of the mixed-layer depth, this topic should be further examined in the future.

We next examine the summer monsoon gyre in the $F^{\text {net }}$ run. The QTCM simulation shows a similar summer monsoon gyre, which is located at the area of the simulated summer monsoon trough (Fig. 10f), but more southwestward than in the observation (Fig. 10b). Both the simulated maximum rainfall difference and monsoon gyre coincide reasonably well with each other. This southwestward shift of the summer monsoon gyre could be due to either the limitation of the model or an involvement of more complicated processes, such as atmosphere-ocean interaction. When fixing $F^{\text {net }}$ in the second wet period (the fixed $F^{\text {net }}$ run), the monsoon gyre disappears (not shown). This implies that the difference in $F^{\text {net }}$ between the first and second wet periods (Fig. 10d) does play an important role in inducing the summer monsoon gyre in the second wet period. Examining the impacts of each component of $F^{\text {net }}$, we allow only one component of $F^{\text {net }}$ to vary with season in each experiment, which is similar to the $F^{\text {net }}$ run. The results show that evaporation is the most important component of $F^{\text {net }}$ for inducing the rainfall of the summer monsoon gyre (Fig. 12a) while the cloud-longwave radiative feedback also plays a role in enhancing the monsoon gyre (Fig. 12b). Figure 10d shows that the main difference in $F^{\text {net }}$ includes not only the enhancement over the WNP, but also the reduction of the land-ocean $F^{\text {net }}$ contrast. Thus, we further divide the evaporation into local and remote components (within and outside the area of the equator $-15^{\circ} \mathrm{N}$ and $110^{\circ}-160^{\circ} \mathrm{E}$, the location of the monsoon gyre in the $F^{\text {net }}$ run) and examine their impacts separately. The results (Figs. 12c and 12d) show that the local and remote evaporation components (or $\left.F^{\text {net }}\right)$ are equally important to the summer monsoon gyre. This implies that the land-ocean contrast of $F^{\text {net }}$ may also affect the deepening of the monsoon trough.

In the QTCM control run with prescribed SST (the CTRL run), the land-sea contrast of $F^{\text {net }}$ (not shown) is stronger than the observation shown in Fig. 7 since QTCM does not include land snow. Thus, an experiment with a reduced longitudinal contrast of $F^{\text {net }}$ (the REDUCED run), which is close to the observations, is conducted. In the CTRL run (Fig. 13b), a weak monsoon 
(a) 2nd-1st Precip: E run

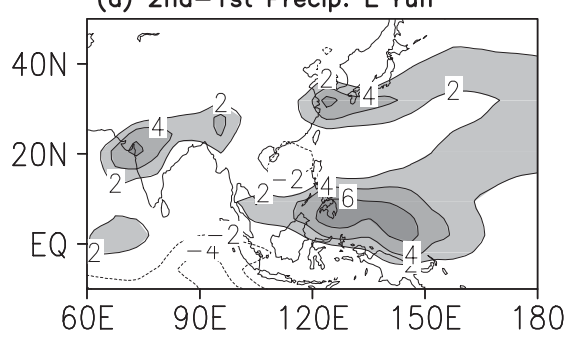

(c) Local E run

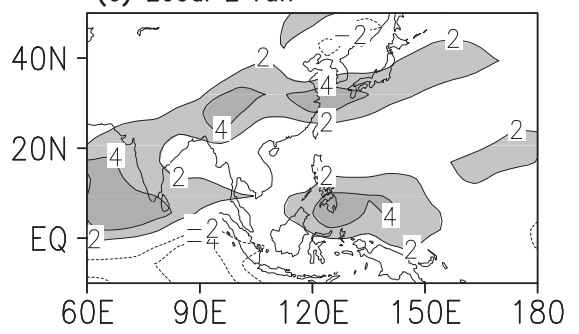

(b) FLW run

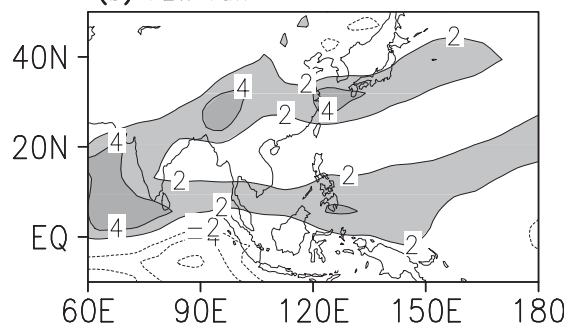

(d) Remote $E$ run

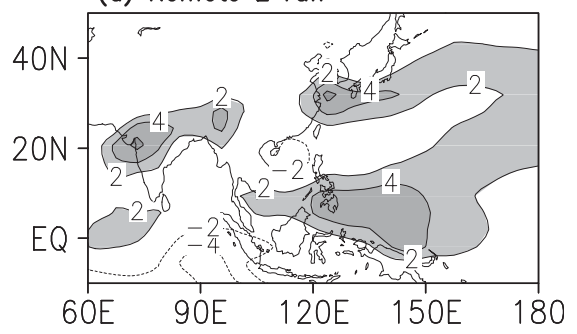

FIG. 12. Precipitation differences of the second minus first wet periods for the (a) evaporation (E) run, (b) longwave radiation (FLW) run, (c) local (within the area of equator $-15^{\circ} \mathrm{N}$ and $110^{\circ}-160^{\circ} \mathrm{E}$ ) evaporation run, and (d) remote (outside the area of equator $-15^{\circ} \mathrm{N}$ and $110^{\circ}-160^{\circ} \mathrm{E}$ ) evaporation run.

trough extends eastward only to the Philippines around $120^{\circ} \mathrm{E}$ in the second wet period. In the REDUCED run, however, the monsoon trough extends much more eastward to the Philippine Sea and the western North Pacific around $150^{\circ} \mathrm{E}$ (Fig. 13d). The associated summer monsoon gyre is also stronger and extends a little more westward (Fig. 13f) than it does in the CTRL run (Fig. 13e). In other words, the weaker the land-sea contrast of $F^{\text {net }}$, the stronger the Asian summer monsoon trough. This result is also consistent with the results shown in Figs. 12c and $12 \mathrm{~d}$. The reduced land-sea contrast of $F^{\text {net }}$ could be induced by either the inclusion of land snow or warmer neighboring oceans via atmosphere-ocean interaction.

Atmosphere-ocean interaction may be important in producing correct precipitation forecasts over the Philippine Sea (Wang and Ding 2008; Wu 2002). Examining the MIXED run (Fig. 14), the monsoon trough extends eastward to around $140^{\circ} \mathrm{E}$ in the second wet period (Fig. $14 \mathrm{~b}$ ), which is more eastward than in the CTRL run (Fig. 13b), and the subtropical ridge extends westward to Japan and Korea, which is more westward than in the CTRL run as well. We note that the SST of the MIXED run is higher than in the CTRL run (not shown). The summer monsoon gyre of the MIXED run (Fig. 14d) is a little more northwestward than in the CTRL run (Fig. 13e), which is closer to the observations (Fig. 10b). The associated precipitation is also stronger than in the CTRL run (Fig. 14c and the shading in Fig. 13e). In an experiment with a seasonal $Q$ flux instead of an annualmean $Q$ flux, the results are very similar to those in the
CTRL run (not shown). This implies that atmosphereocean interaction could play a role in creating the summer monsoon gyre, particularly when the influence of the ocean dynamics is relatively weak.

\section{The dry phase}

The winter period is a dry season over the WNP-EA region. During this period, the northwesterly flow associated with the Siberian high dominates the northern part of the WNP-EA region (north of $30^{\circ} \mathrm{N}$ ) while the northeasterly flow dominates the southern part of the region (Fig. 15a). The strength of the winter monsoon flow is related to the longitudinal pressure gradient associated with the Siberian high and the Aleutian low. When the Asian winter monsoon is strong, the northerly wind component is strengthened, the Siberian high is enhanced, and the Aleutian low is deepened (Jhun and Lee 2004). The winter northerly wind component transports cold and dry air to eastern China, Korea, Japan, Taiwan, and the Philippines from the SiberianMongolian region, as shown in Fig. 15b. The northwesterly flow (north of $30^{\circ} \mathrm{N}$ ) is deep vertically and can be found throughout the whole troposphere (not shown), while the northeasterly flow (south of $30^{\circ} \mathrm{N}$ ) is much shallower and concentrates at the lower troposphere (below $800 \mathrm{hPa}$ ). The dry and cold advection of the winter monsoon is found over the southern part of the WNP-EA region (south of $30^{\circ} \mathrm{N}$ ) therefore concentrates only at the lower troposphere. Above the layer of strong 
(a) Prec;1000hPa stream (CTRL): 1st

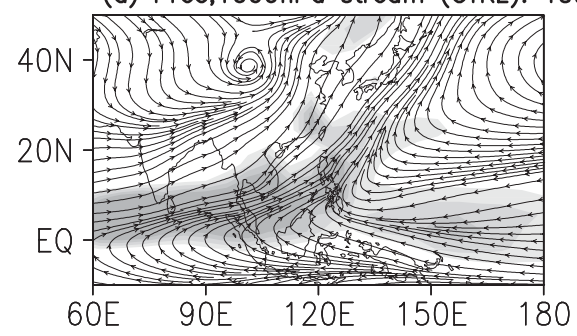

(c) REDUCED run: 1 st

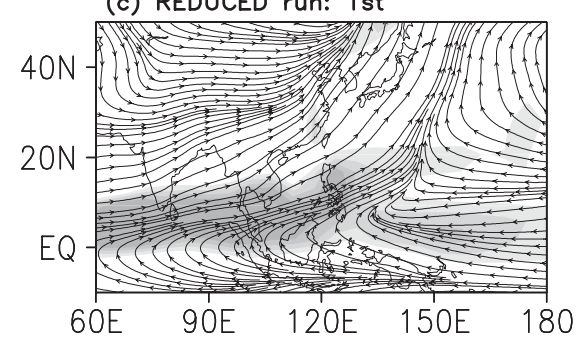

(e) 2 nd-1st: CTRL run

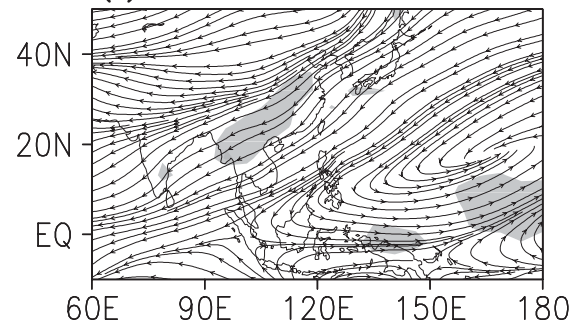

(b) CTRL run: 2 nd

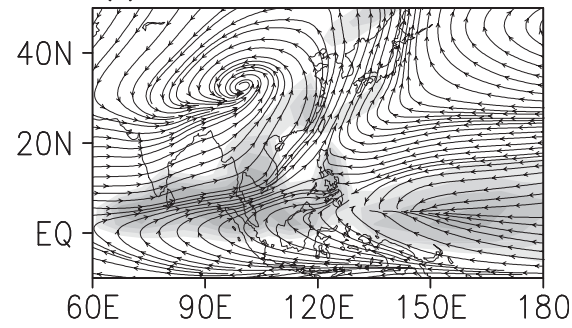

(d) REDUCED run: 2nd

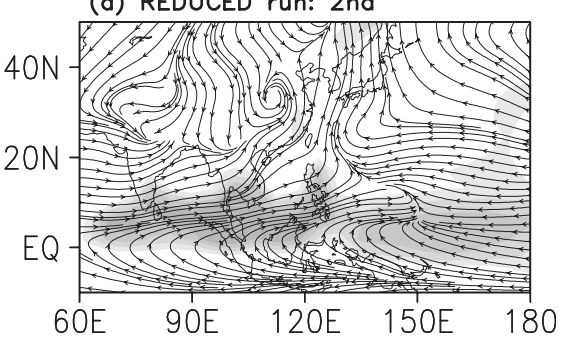

(f) 2 nd-1st: REDUCED run

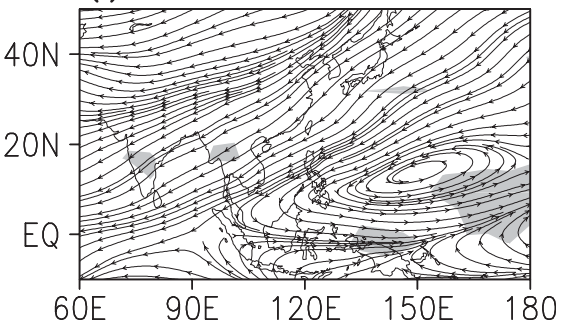

FIG. 13. Spatial distributions of the 1000-hPa streamline shaded with the precipitation over $6 \mathrm{~mm} \mathrm{day}^{-1}$ in (a) the first and (b) second wet periods of the CTRL run and in (c) the first and (d) second wet periods of the REDUCED run. The differences between the 1000-hPa streamline and precipitation (shaded for precipitation over $2 \mathrm{~mm} \mathrm{day}^{-1}$ ) between the second and first wet periods for (e) the CTRL run and (f) the REDUCED run.

dry and cold advection, a westerly flow at the midtroposphere brings relatively moist air from the Bay of Bengal into southeastern China and the southern part of the WNP (Figs. 15c and 15d). This horizontal moisture advection in the middle troposphere is associated with frontal systems, which are the main processes for winter precipitation over the southern part of the WNP-EA region.

In the winter period, the Siberian high dominates the entire WNP-EA region (Fig. 15a). Over the northern part of the WNP-EA region, the rainband over the far east of the region (Fig. 3a) is induced by winter storm activities (e.g., Hanson and Long 1985; Asai et al. 1988; Nakamura et al. 2002; Chan and Li 2004). The cold air over the Asian continent moves over the relatively warm surface of the Pacific Ocean and induces strong convection as well as the associated winter rainfall. Over the regions of southern China and Taiwan, however, the pressure surge associated with the frontal systems is the main process for inducing the winter rainfall over these regions (e.g., Zhang et al. 1997; Compo et al. 1999; Chan and Li 2004). The cold air associated with the Siberian high moves southward and lifts warm air over the southern part of the WNP-EA region, such as southern China and Taiwan. An elongated anticyclonic circulation at $700 \mathrm{hPa}$ between $10^{\circ}$ and $20^{\circ} \mathrm{N}$ (Fig. 15c) coincides with the minimum rainfall that separates the tropical convection zones and the winter monsoon rainband (Fig. 3a). A local precipitation maximum is found east of Taiwan. This maximum is associated with upward moisture advection, that is, $-\left\langle\omega \partial_{p} q\right\rangle>0$, which may be due to a topographic effect, considering that, with northeasterly winds in the background, more than half of the island of Taiwan is covered by mountains, many of which are above $3000 \mathrm{~m}$ high. Detailed examination is needed for the further understanding of this local maximum precipitation.

\section{The transition phase}

Over the WNP-EA sector, the two transition periods between the wet and dry phases are spring and fall. The spring period represents a transition from the dry to the 
(a) Prec; $1000 \mathrm{hPa}$ stream (MIXED): 1 st

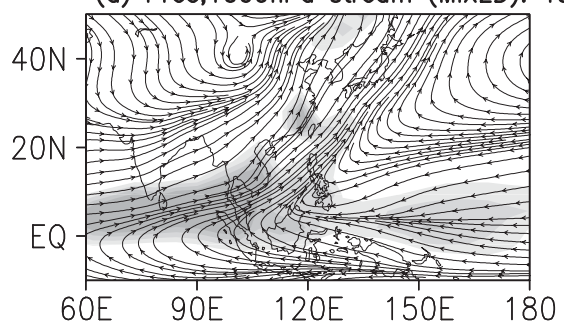

(c) 2nd-1st Prec (MIXED run)

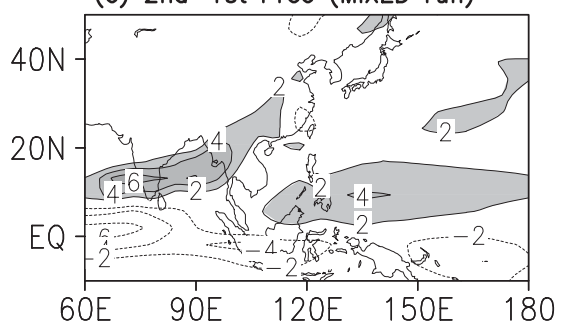

(b) MIXED run: 2 nd

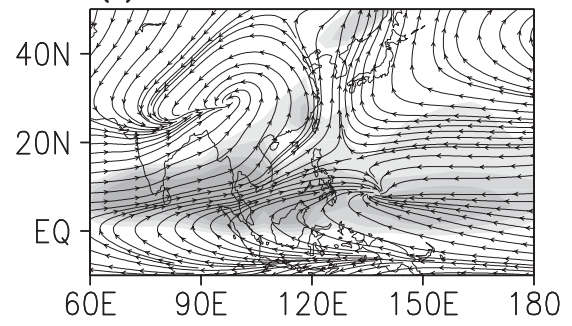

(d) $2 \mathrm{nd}-1 \mathrm{st} 1000 \mathrm{hPa}$ stream (MIXED)

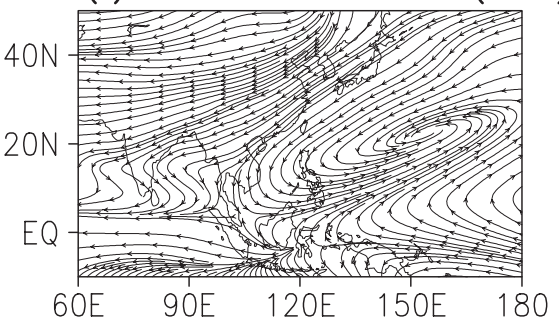

FIG. 14. Spatial distributions of the 1000-hPa streamline shaded with the precipitation over $6 \mathrm{~mm} \mathrm{day}{ }^{-1}$ for the MIXED run in (a) the first and (b) second wet periods. Differences of the second minus first wet periods for (c) precipitation and (d) the 1000-hPa streamline.

wet phase, while the fall period is a transition from the wet to the dry phase. Even though the solar insolation is almost identical in these two periods, their precipitation patterns are different as shown in Figs. 3d and 3e. Here, we will examine the possible processes that supply moisture for the spring and fall rainfall.

\section{a. The spring period}

Figure 16a shows low-level circulation $(850 \mathrm{hPa})$ in the spring period. At this time the northerly monsoon winds associated with the Siberian high are weakened and retreat to north of $25^{\circ} \mathrm{N}$, compared to those of the winter period, as shown in Fig. 15a; the Aleutian low also weakens and retreats northward. On the other hand, the low-level circulation associated with the $\mathrm{Pa}$ cific subtropical high extends westward to Indochina, so the prevailing winds over the South China Sea and the southern part of the WNP-EA region change from northerly in winter to southerly in spring. The northerly winds can be found only at $1000 \mathrm{hPa}$ (not shown), the (a) $925 \mathrm{hPa}$ streamline

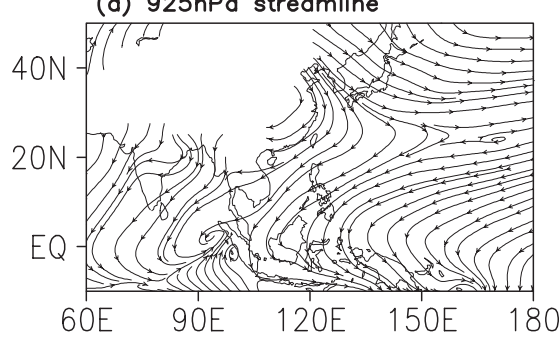

(c) $700 \mathrm{hPa}$ streamline

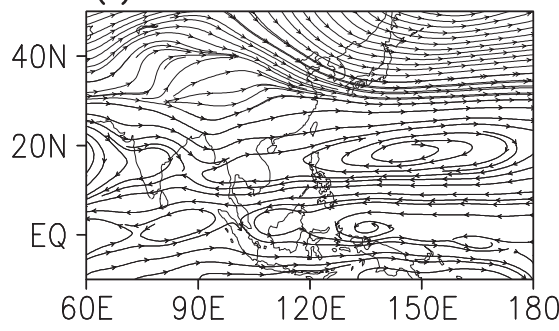

Winter

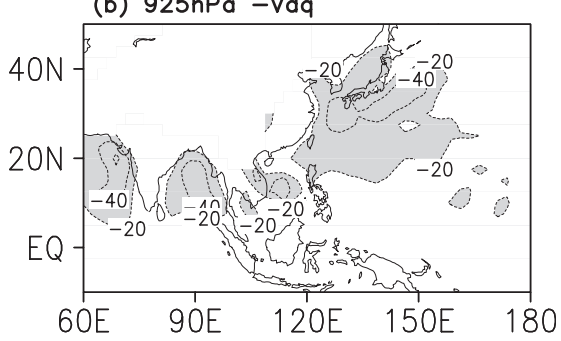

(d) $700 \mathrm{hPa}-\mathrm{Vdq}$

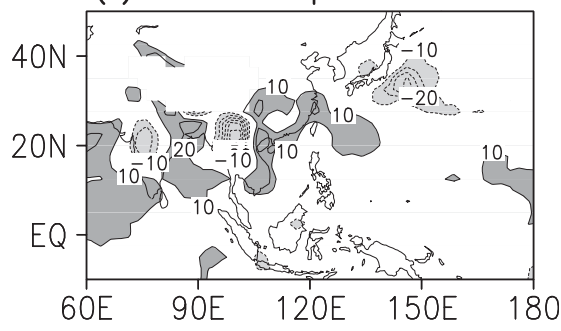

FIG. 15. The observed $925-\mathrm{hPa}$ (a) streamline and (b) $-\mathbf{v} \cdot \nabla q$, and the $700-\mathrm{hPa}$ (c) streamline and (d) $-\mathbf{v} \cdot \nabla q$ in the winter period. The contour interval is $20 \mathrm{~W} \mathrm{~m}^{-2}$ in (b) and $10 \mathrm{~W} \mathrm{~m}^{-2}$ in (d). 


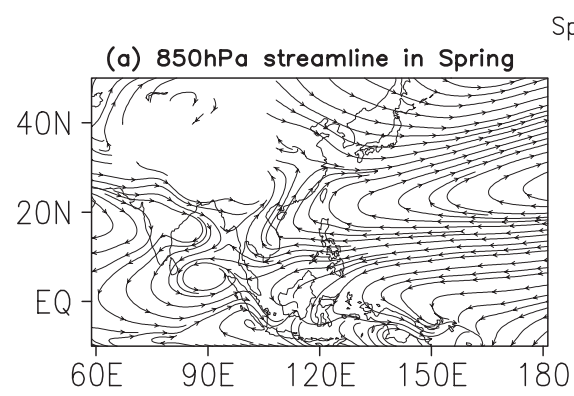

Spring

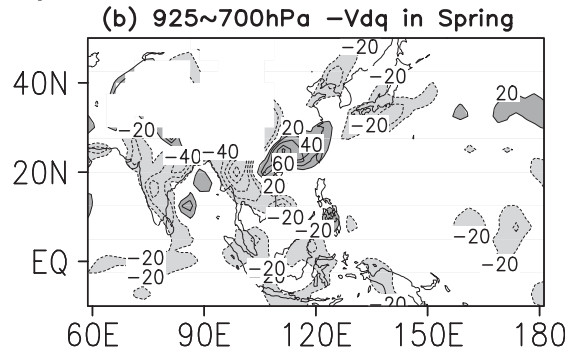

(c) $850 \mathrm{hPa}$ streamline in Fall
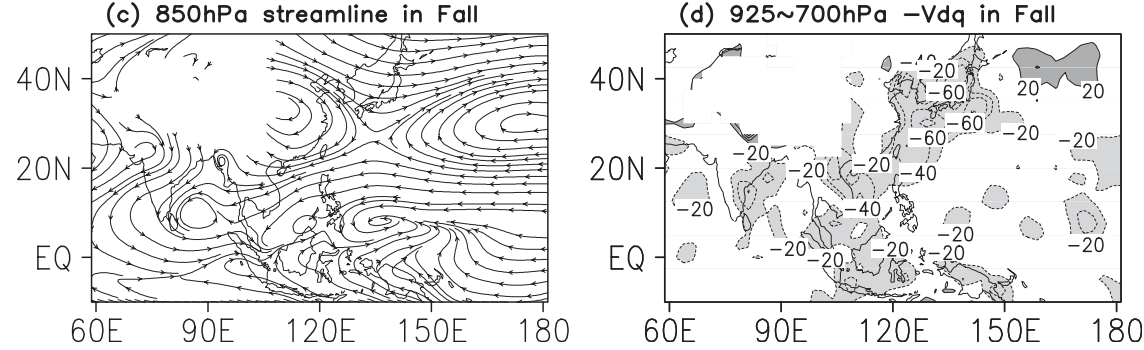

FIG. 16. The observed (a) 850 -hPa streamline and (b) $-\mathbf{v} \cdot \nabla q$ integrated over $925-700 \mathrm{hPa}$ in the spring period. (c),(d) As in (a),(b) but in the fall period. The contour interval is $20 \mathrm{~W} \mathrm{~m}^{-2}$.

lowest troposphere. In other words, the spring circulation over these regions is more like a summer pattern dominated by a flow from the south. In the winter period, the temperature over the North Pacific Ocean is warmer than that over the Asian continent. As the season progresses from winter to spring, the continent warms faster than the neighboring ocean at the same latitude because of its smaller heat capacity. This difference in warming rate tends to create a negative longitudinal temperature gradient and the associated positive geopotential height gradient (not shown); thus, in the spring period, the northerly winter monsoon winds start to retreat, and the southerly winds begin to dominate the southern part of the WNP-EA region. The relationship between the spring rainfall and the longitudinal temperature gradient has been discussed by Tian and Yasunari (1998). In this period, the meridional temperature gradient does not change sign (not shown), such as in the first wet period, so the Asian summer monsoon circulation has not yet been established $(\mathrm{Li}$ and Yanai 1996; Wang and Ding 2008).

With the southerly winds of the Pacific subtropical high dominating the southern part of the WNP-EA region, horizontal advection of moist and warm air from the south can be expected along the western side of the subtropical high. Figure 16b shows low-level moisture advection in the spring period. A southwest-northeast band of positive $-\mathbf{v} \cdot \nabla q$ is found, which is roughly consistent with the spring rainband shown in Fig. 3d. This positive $-\mathbf{v} \cdot \nabla q$ band is in the lower troposphere and is stronger than that in the winter period (Fig. 15d).
This finding implies that the spring rain is associated with the horizontal moisture advection at lower troposphere, which is related to the westward extent of the Pacific subtropical high. The subsidence associated with the Pacific subtropical high separates the spring rainband from the tropical convection (Fig. 3d). The spring rainband is tilted from southwest to northeast, similar to the southwest-northeast-tilting pre-mei-yu/mei-yu rainband (Figs. 3b and 3d). However, since the Asian summer monsoon circulation has not yet been formed in the spring period, the horizontal moisture advection is associated only with the Pacific subtropical high. In comparison, the horizontal moisture advection in the first wet period is associated with the Asian summer monsoon circulation, the Pacific subtropical high, and a crossequatorial flow (Fig. 5a), so the convergence of the moisture flux and the associated rainfall is much stronger in the first wet period than in spring. Figure 17a shows the variations of the low-level moisture advection averaged over $115^{\circ}-135^{\circ} \mathrm{E}$. In spring, positive moisture advection occurs around $25^{\circ} \mathrm{N}$, where the spring rainband is located (Fig. 1). In the first wet period, after the onset of the Asian summer monsoon, the positive moisture advection becomes much stronger and coincides well with the premei-yu/mei-yu rainband. This further indicates the importance of horizontal moisture advection for the spring and the pre-mei-yu/mei-yu rainfall.

\section{b. The fall period}

During the fall period, the colder Asian continent induces a low-level anticyclonic circulation (Fig. 16c) 

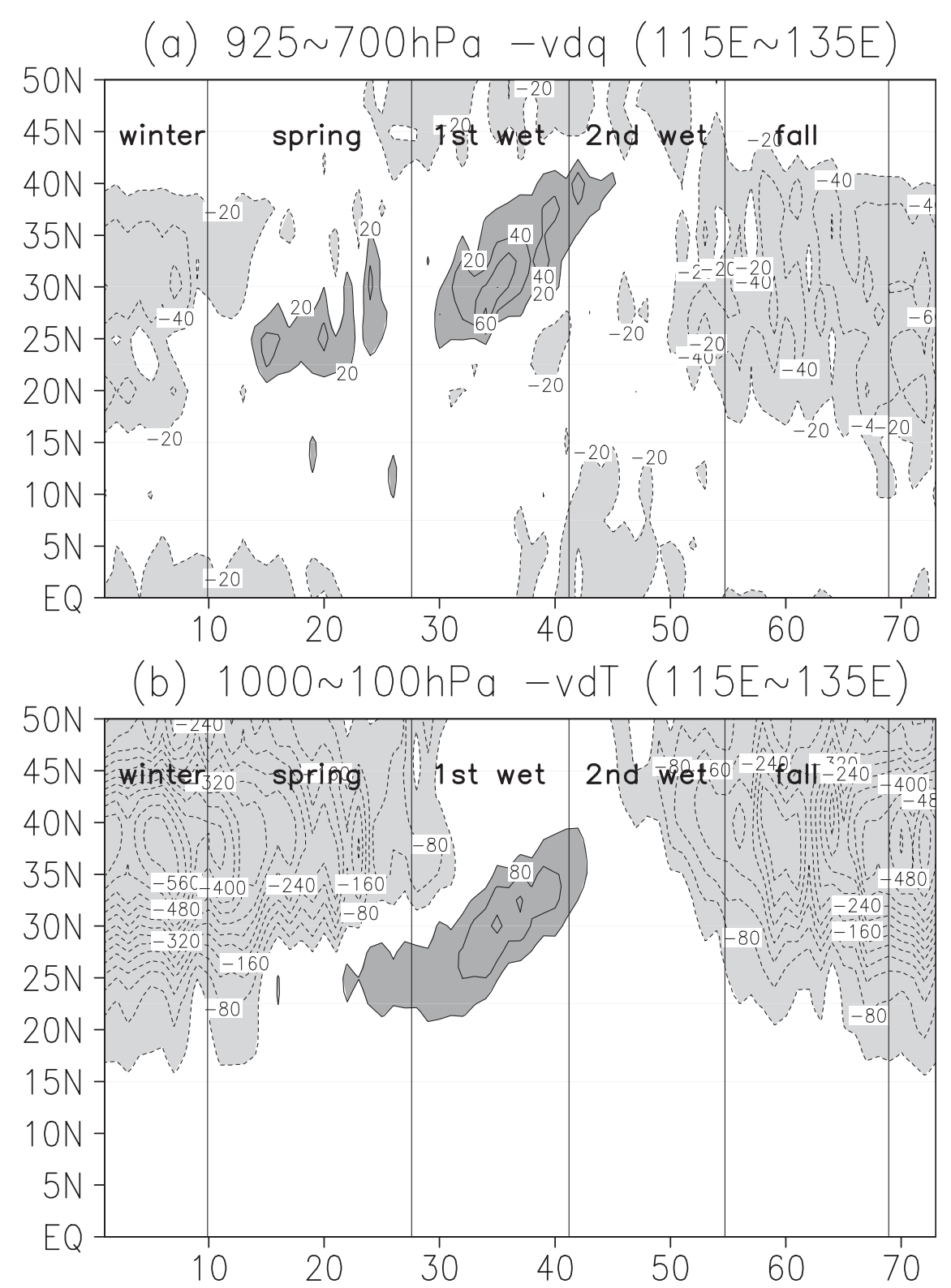

FIG. 17. Averages over $115^{\circ}-135^{\circ} \mathrm{E}$ for the observed (a) $-\mathbf{v} \cdot \nabla q$ integrated over $925-700 \mathrm{hPa}$ and (b) $-\mathbf{v} \cdot \nabla T$ integrated over $1000-100 \mathrm{hPa}$. The contour interval is $20 \mathrm{~W} \mathrm{~m}^{-2}$ in (a) and $40 \mathrm{~W} \mathrm{~m}^{-2}$ in (b).

and initiates the Asian winter monsoon. A strong northerly winter monsoon flow blows over the entire WNPEA region and transports dry and cold air from Mongolia to the WNP-EA region (Fig. 16d). This flow is associated with a continental high centered at the Loess Plateau around $35^{\circ} \mathrm{N}$ and $110^{\circ} \mathrm{E}$, and the induced subsidence dominates almost the entire troposphere over the northern part of WNP-EA region (not shown). Compared to the previous precipitation period, the second wet period, the Pacific subtropical high in the fall period is weakened and retreats eastward. The cold advection associated with anticyclonic circulation extends southward over the WNP-EA region as the season progresses (Fig. 17b). Thus, the circulation in the fall period is more like a winter pattern, controlled by a flow from the north.

As discussed in section 3, the fall precipitation over the WNP-EA region is dominated by frontal systems in the north and tropical convection in the south (Figs. 1 and $3 \mathrm{e}$ ). The precipitation associated with frontal systems is similar to that of the winter period, which is characterized by large-scale lifting and winter storm activities, but is different from the tilting rainband in 
(a) Spring SST(p14-p27)

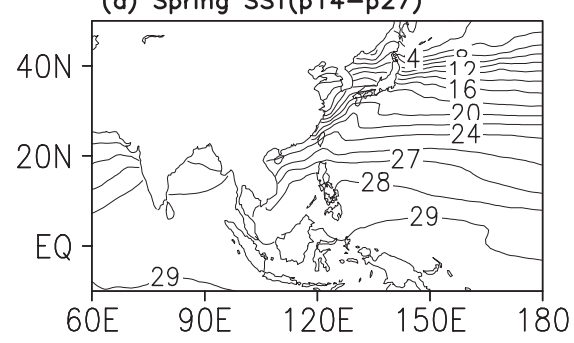

(c) Fall-Spring Prec

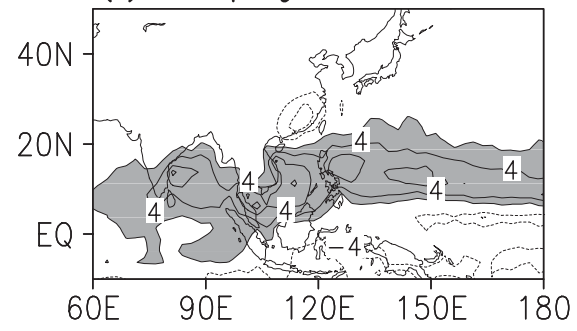

(b) Fall SST(p54-p67)

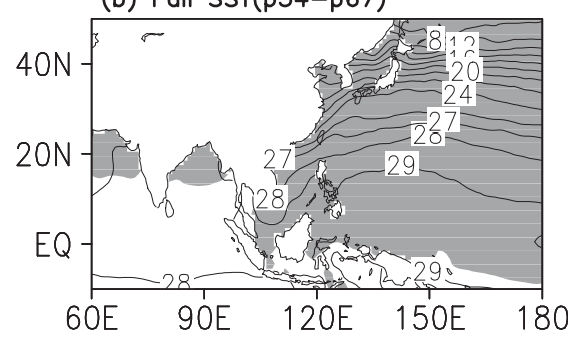

(d) Fall-Spring -vdq (925 700hPa)

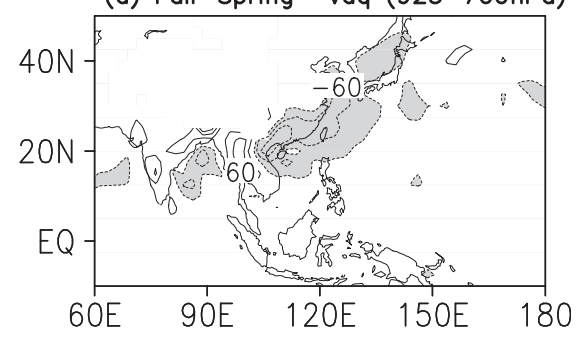

FIG. 18. The observed SST $\left({ }^{\circ} \mathrm{C}\right)$ in the (a) spring and (b) fall periods. The differences of the fall minus spring periods for (c) the CMAP precipitation (with a $2 \mathrm{~mm} \mathrm{day}^{-1}$ interval) and (d) the observed $-\mathbf{v} \cdot \nabla q$ integrated over $900-700 \mathrm{hPa}$. The shading in (b) is for the area with the fall SST that is higher than the spring SST. The contour interval for (d) is $30 \mathrm{~W} \mathrm{~m}^{-2}$.

spring, which is associated with horizontal moisture advection. The tropical convection is associated with the retreat of the WNP summer monsoon system, so the precipitation over the southern part of the WNP-EA region may also be associated with warm SST via $F^{\text {net }}$. In the spring period, the area of SSTs warmer than $29^{\circ} \mathrm{C}$ barely reaches $5^{\circ} \mathrm{N}$ in the WNP (Fig. 18a). In the fall period, on the other hand, the $29^{\circ} \mathrm{C}$ line can reach as far north as $15^{\circ} \mathrm{N}$ (Fig. 18b). Almost the entire Pacific Ocean north of the equator is warmer in fall than in spring (shaded in Fig. 18b). This indicates that the ocean surface condition in the fall period is more favorable for convection than in the spring period. Thus, the associated fall precipitation over the southern part of the WNP-EA region (between $5^{\circ}$ and $20^{\circ} \mathrm{N}$ ) is much higher than the spring precipitation (Fig. 18c) even though an atmospheric condition with strong dry and cold advection (Fig. 18d) is usually not favorable for convection (Wang and Ding 2008).

\section{Discussion and conclusions}

Based on the CMAP pentad precipitation, five major precipitation periods are identified over the western North Pacific-East Asian (WNP-EA) region: spring, the first and second wet periods, fall, and winter. Each period has its own precipitation and circulation patterns, which are associated with land-ocean configuration and solar forcing. The first and second wet periods are associated with the wet phase of the Asian monsoon system, while the winter period is related to its dry phase. Between the wet and dry phases, two transitions are the spring and fall periods. The spring period is a transition from the dry into the wet phase of the Asian monsoon system, while the fall period is a transition from the wet to the dry phase.

The most important rainy season over the WNP-EA region occurs in the boreal summer, which is dominated by the Asian summer monsoon circulation induced by a land-ocean contrast of the net energy into the atmospheric column $F^{\text {net }}$ (Fig. 7). Here, $F^{\text {net }}$ is equivalent to the convergence of the vertically integrated MSE and has a stronger longitudinal than meridional land-ocean contrast. The abrupt northward jump of precipitation over the WNP divides the boreal summer into the first and second wet periods. In the first wet period, the northern part of the WNP region is dominated by the southwest-northeast-tilting pre-mei-yu/mei-yu rainband, which is mainly associated with the horizontal moisture advection directly via the convergence of moisture flux, and indirectly via the dynamic feedback of vertical motion. Besides the horizontal moisture advection, the premei-yu/mei-yu rainband is also associated with horizontal temperature advection (Figs. 1 and 17). The horizontal temperature and moisture advection is associated with the Asian summer monsoon circulation, so the pre-meiyu/mei-yu rainband moves northward as the land-ocean $F^{\text {net }}$ contrast is enhanced. The southern part of the WNP-EA region, on the other hand, is dominated by tropical convection over the South China Sea and the 
Philippine Sea, which is associated with the dynamic feedback of upward motion induced by positive $F^{\text {net }}$.

In the second wet period, the major rainy system is the WNP summer monsoon gyre, which is an oceanic summer monsoon. This summer monsoon gyre is associated with the eastward extension of the Asian summer monsoon trough, which creates favorable conditions for the generation of tropical cyclones. The deepening of the monsoon trough also weakens the horizontal moisture and temperature advection, so the tilting rainband almost disappears in this period. The rainfall of the WNP summer monsoon gyre is maintained by the convergence of the moisture flux associated with the dynamic feedback of ascending motion, which is partially induced by local warmer SSTs via positive $F^{\text {net }}$. During this period, the WNP SST reaches its maximum strength and the $29^{\circ} \mathrm{C}$ line extends northeastward to $25^{\circ} \mathrm{N}$ (Fig. 10c). Meanwhile, the abrupt onset of the WNP summer monsoon gyre and its variation coincide well with the variation of $F^{\text {net }}$ (Figs. 10a and 10b). Cloud-radiation, especially longwave radiation, also has a positive feedback to the rainfall. Besides the local process, the land-sea contrast of $F^{\text {net }}$ and atmosphere-ocean interaction can also influence the Asian summer monsoon trough.

The winter period is a dry season over the WNP-EA region and is dominated by northerly winter monsoon winds, which occur only at the lower troposphere. A major rainband occurs east of Japan and a small area of maximum precipitation is also found northeast of Taiwan. The precipitation can be associated with two processes: midlatitude winter storms associated with cold air over a warm ocean, and large-scale lifting associated with a pressure surge from the north.

The two transition periods between the dry and wet phases also exhibit different atmospheric and oceanic conditions, albeit with a similar solar radiative forcing during spring and fall. The spring rainfall is dominated by a southwest-northeast-tilting rainband. The fall rainfall, on the other hand, is dominated by a frontal rainfall system over the northern part of the WNP-EA region and weak tropical convection over the southern part of the WNP-EA region. For the atmospheric circulation, the spring period is dominated by southerly winds over the southern part of the WNP-EA region, while the fall period is controlled by northerly winds over the WNPEA region. Thus, the atmospheric conditionss in the spring period are similar to that of the summer period, while the fall period is similar to that of the winter period. In contrast, the ocean surface conditions for these two periods are reversed. The WNP SSTs are colder in the spring period than in the fall period, so the ocean surface conditions in the spring period are more like those of the winter period with colder SSTs, while the fall period is similar to that of the summer period with warmer SSTs over the WNP.

The differences in the atmospheric and ocean surface conditions between the spring and fall periods are associated with the delayed response of oceans to the solar heating, due to their large heat capacity (Chang et al. 2005; Wang and Ding 2008). In the spring period when the sun moves from the Southern to the Northern Hemisphere, the atmosphere over the Asian continent becomes warmer while the WNP is still relatively cold. Therefore, the winter northerly flow retreats northward and the southerly flow associated with the Pacific subtropical high starts to dominate the southern part of the WNP-EA sector. The atmosphere begins to favor precipitation due to horizontal moisture advection at lower troposphere, which is different from a typical winter frontal system, while the SST over the WNP remains cold and relatively disfavors convection. In this period, the longitudinal land-ocean contrast of the temperature is reversed, but not the meridional land-ocean contrast. Thus, the horizontal moisture convergence is more closely associated with the westward extension of the Pacific subtropical high. In the fall period, on the other hand, the atmospheric and ocean surface conditions are completely reversed. The Asian continent quickly cools as the sun moves to the Southern Hemisphere, causing the northerly flow associated with the cold Asian continent to extend southward and transport cold and dry air to the northern part of the WNP-EA region. This cold and dry advection creates unfavorable atmospheric conditions for convection. However, the fall SSTs of the WNP are relatively warmer than in the spring because of the slower cooling pace of the ocean. Thus, the ocean surface conditions over the WNP still relatively favor convection even though the atmospheric conditions of the northern part of the WNPEA region have already been dominated by northerly winds. Overall, the spring rainfall is induced by a process of horizontal moisture advection similar to that of the premei-yu/mei-yu rainfall in the first wet period, but is comparatively weaker since the summer monsoon circulation has not yet been established. The fall rainfall, on the other hand, is stronger than the winter rainfall due to warmer SSTs. The tilting rainband in the northern part of the WNP-EA is associated with the frontal system, which is not induced by horizontal moisture advection, such as in the spring period.

Acknowledgments. This work was supported under National Science Council Grant 96-2628-M-001-019. We thank Professors Chung-Hsiung Sui, Chih-Hua Tsou, and Jia-Yuh Yu for useful comments. The NCEPDOE Reanalysis-2 data were provided by the NOAACIRES Climate Diagnostics Center, Boulder, Colorado, 
via their Web site (information online at http://www. cdc.noaa.gov/).

\section{REFERENCES}

Annamalai, H., J. M. Slingo, K. R. Sperber, and K. Hodges, 1999: The mean evolution and variability of the Asian summer monsoon: Comparison of ECMWF and NCEP-NCAR reanalyses. Mon. Wea. Rev., 127, 1157-1186.

Asai, T., Y. Kodama, and J.-C. Zhu, 1988: Long-term variations of cyclone activities in East Asia. Adv. Atmos. Sci., 5, 149-158.

Betts, A. K., and M. J. Miller, 1993: The Betts-Miller scheme. The Representation of Cumulus Convection in Numerical Models of the Atmosphere, Meteor. Monogr., No. 46, Amer. Meteor. Soc., 107-121.

Chan, J. C. L., and C. Li, 2004: The East Asia winter monsoon. East Asian Monsoon, C.-P. Chang, Eds., World Scientific Publishing, 54-106.

Chang, C.-P., and G. T. Chen, 1995: Tropical circulations associated with southwest monsoon onset and westerly surges over the South China Sea. Mon. Wea. Rev., 123, 3254-3267.

_ - Z. Wang, J. McBride, and C.-H. Liu, 2005: Annual cycle of southeast Asia-maritime continent rainfall and the asymmetric monsoon transition. J. Climate, 18, 287-301.

Chen, C.-S., and Y.-L. Chen, 2003: The rainfall characteristics of Taiwan. Mon. Wea. Rev., 131, 1323-1341.

Chou, C., 2003: Land-sea heating contrast in an idealized Asian summer monsoon. Climate Dyn., 21, 11-25.

, 2004: Establishment of the low-level wind anomalies over the western North Pacific during ENSO development. J. Climate, 17, 2195-2212.

_ , and J. D. Neelin, 1996: Linearization of a longwave radiation scheme for intermediate tropical atmospheric models J. Geophys. Res., 101, 15 129-15 145.

_ , and - 1999: Cirrus detrainment-temperature feedback. Geophys. Res. Lett., 26, 1295-1298.

$\longrightarrow$, and - 2003: Mechanisms limiting the northward extent of the northern summer monsoons over North America, Asia and Africa. J. Climate, 16, 406-425.

$\longrightarrow, \ldots$, and H. Su, 2001: Ocean-atmosphere-land feedbacks in an idealized monsoon. Quart. J. Roy. Meteor. Soc., 127, 1869-1891.

_ - J.-Y. Tu, and J.-Y. Yu, 2003: Interannual variability of the western North Pacific summer monsoon: Differences between ENSO and non-ENSO years. J. Climate, 16, 2275-2287.

—, L.-F. Huang, J.-Y. Tu, L. Tseng, and Y.-C. Hsueh, 2009: El Niño impacts on precipitation in the western North PacificEast Asian sector. J. Climate, 22, 2039-2057.

Chu, P.-S., 2002: Large-scale circulation features associated with decadal variations of tropical cyclone activity over the central North Pacific. J. Climate, 15, 2678-2689.

Compo, G. P., G. N. Kiladis, and P. J. Webster, 1999: The horizontal and vertical structure of East Asian winter monsoon pressure surges. Quart. J. Roy. Meteor. Soc., 125, 29-54.

Ding, Y., 1992: Summer monsoon rainfalls in China. J. Meteor Soc. Japan, 70, 373-396.

_ An overview. Meteor. Atmos. Phys., 89, 117-142.

Fu, Q., and K. N. Liou, 1993: Parameterization of the radiative properties of cirrus clouds. J. Atmos. Sci., 50, 2008-2025.

Hanson, H. P., and B. Long, 1985: Climatology of cyclongenesis over the east China Sea. Mon. Wea. Rev., 113, 697-707.
Harshvardhan, R. Davies, D. A., Randall, and T. G. Corsetti, 1987: A fast radiation parameterization for general circulation models. J. Geophys. Res., 92, 1009-1016.

Hsu, H.-H., and X. Liu, 2003: Relationship between the Tibetan Plateau heating and East Asian summer monsoon rainfall. Geophys. Res. Lett., 30, 2066, doi:10.1029/2003GL017909.

—, and S.-M. Lin, 2007: Asymmetry of the tripole rainfall pattern during East Asian summer. J. Climate, 20, 44434458.

, C.-T. Terng, and C.-T. Chen, 1999: Evolution of large-scale circulation and heating during the first transition of Asian summer monsoon. J. Climate, 12, 793-810.

Hung, C.-W., H.-H. Hsu, and M.-M. Lu, 2004: Decadal oscillation of spring rain in northern Taiwan. Geophys. Res. Lett., 31, L22206, doi:10.1029/2004GL021344.

Jhun, J.-G., and E.-J. Lee, 2004: A new East Asian winter monsoon index and associated characteristics of the winter monsoon. $J$. Climate, 17, 711-726.

Jiang, Z., G. T.-J. Chen, and M.-C. Wu, 2003: Large-scale circulation patterns associated with heavy spring rain events over Taiwan in strong ENSO and non-ENSO years. Mon. Wea. Rev., 131, 1769-1782.

Kanamitsu, M., W. Ebisuzaki, J. Woollen, S.-K. Yang, J. J. Hnilo, M. Fiorino, and G. L. Potter, 2002: NCEP-DOE AMIP-II Reanalysis (R-2). Bull. Amer. Meteor. Soc., 83, 1631-1643.

Kara, A. B., P. A. Rochford, and H. E. Hurlburt, 2003: Mixed layer depth variability over the global ocean. J. Geophys. Res., 108, 3079, doi:10.1029/2000JC000736.

Lau, K.-M., and H. T. Wu, 2001: Principal modes of rainfall-SST variability of the Asian summer monsoon: A reassessment of the monsoon-ENSO relationship. J. Climate, 14, 2880-2895.

Lau, N.-C., and M. J. Nath, 2006: ENSO modulation of the interannual and intraseasonal variability of the East Asian monsoon-A model study. J. Climate, 19, 4508-4530.

Li, C., and M. Yanai, 1996: The onset and interannual variability of the Asian summer monsoon in relation to land-sea thermal contrast. J. Climate, 9, 358-375.

LinHo, and B. Wang, 2002: The time-space structure of the AsianPacific summer monsoon: A fast annual cycle view. J. Climate, 15, 2001-2019.

Liu, X., and M. Yanai, 2001: Relationship between the Indian monsoon rainfall and the tropospheric temperature over the Eurasian continent. Quart. J. Roy. Meteor. Soc., 127, 909-937.

Masunaga, H., T. S. L'Ecuyer, and C. D. Kummerow, 2005: Variability in the characteristics of precipitation systems in the tropical Pacific. Part I: Spatial structure. J. Climate, 18, 823-840.

Murakami, T., 1987: Effects of the Tibetan Plateau. Monsoon Meteorology, C.-P. Chang and T. N. Krishnamurti, Eds., Oxford University Press, 26-59.

_ continent and western North Pacific. J. Meteor. Soc. Japan, 72, 719-745.

Nakamura, H., T. Izumi, and T. Sampe, 2002: Interannual and decadal modulations recently observed in the Pacific storm track activity and East Asia winter monsoon. J. Climate, 15, $1855-1874$

Neelin, J. D., 2007: Moist dynamics of tropical convection zones in monsoons, teleconnections and global warming. The Global Circulation of the Atmosphere, T. Schneider and A. Sobel, Eds., Princeton University Press, 267-301.

, and I. M. Held, 1987: Modeling tropical convergence based on the moist static energy budget. Mon. Wea. Rev., 115, $3-12$. 
, and J.-Y. Yu, 1994: Modes of tropical variability under convective adjustment and the Madden-Julian oscillation. Part I: Analytical theory. J. Atmos. Sci., 51, 1876-1894.

— model—Formulation. J. Atmos. Sci., 57, 1741-1766.

Reynolds, R. W., N. A. Rayner, T. M. Smith, D. C. Stokes, and W. Wang, 2002: An improved in situ and satellite SST analysis for climate. J. Climate, 15, 1609-1625.

Rodwell, M. J., and B. J. Hoskins, 1996: Monsoons and the dynamics of deserts. Quart. J. Roy. Meteor. Soc., 122, 13851404.

$\longrightarrow$, and - 2001: Subtropical anticyclones and summer monsoons. J. Climate, 14, 3192-3211.

Sobel, A. H., and C. S. Bretherton, 2000: Modeling tropical precipitation in a single column. J. Climate, 13, 4378-4392.

Stevens, B., J. Duan, J. C. McWilliams, M. Münnich, and J. D. Neelin, 2002: Entrainment, Rayleigh friction, and boundary layer winds over the tropical Pacific. J. Climate, 15, 30-44.

Tian, S. F., and T. Yasunari, 1998: Climatological aspects and mechanisms of spring persistent rains over central China. $J$. Meteor. Soc. Japan, 76, 57-71.

Ueda, H., and T. Yasunari, 1996: Maturing process of the summer monsoon over the western North Pacific-A coupled oceanatmosphere system. J. Meteor. Soc. Japan, 74, 493-508.

- , and _ 1998: Role of warming over the Tibetan Plateau in early onset of the summer monsoon over the Bay of Bengal and the South China Sea. J. Meteor. Soc. Japan, 76, 1-12.

$\longrightarrow,-$, and R. Kawamura, 1995: Abrupt seasonal change of large-scale convective activity over the western Pacific in the northern summer. J. Meteor. Soc. Japan, 73, 795-809.

Wang, B., and X. Xu, 1997: Northern Hemispheric summer monsoon singularities and climatological intraseasonal oscillation. J. Climate, 10, 1071-1085.

— monsoon. J. Climate, 15, 386-398.

— variation in the tropics. Dyn. Atmos. Oceans, 44, 165-183.

- - R. Wu, and X. Fu, 2000: Pacific-East Asian teleconnection: How does ENSO affect East Asian climate? J. Climate, 13, 1517-1536.

— _ _ , and K.-M. Lau, 2001: Interannual variability of the Asian summer monsoon: Contrasts between the Indian and the western North Pacific-East Asian monsoons. J. Climate, 14, 4073-4090.

—, LinHo, Y. Zhang, and M.-M. Lu, 2004: Definition of South China Sea monsoon onset and commencement of the East Asia summer monsoon. J. Climate, 17, 699-710.

Webster, P. J., 1987: The elementary monsoon. Monsoons, J. S. Fein and P. L. Stephens, Eds., John Wiley and Sons, 3-32.
, V. O. Magaña, T. N. Palmer, J. Shukla, R. A. Tomas, M. Yanai, and T. Yasunari, 1998: Monsoons: Processes, predictability, and the prospects for prediction. J. Geophys. Res., 103,14 451-14 510.

Wu, R., 2002: Processes for the northward advance of the summer monsoon over the western North Pacific. J. Meteor. Soc. Japan, 80, 67-83.

— monsoon onset over the western North Pacific and the underlying processes. J. Climate, 13, 2483-2501.

- , and - 2001: Multi-stage onset of the summer monsoon over the western North Pacific. Climate Dyn., 17, 277-289.

— Z. Z.Z. Hu, and B. P. Kirtman, 2003: Evolution of ENSOrelated rainfall anomalies in East Asia. J. Climate, 16, 3742-3758.

Xie, P., and P. A. Arkin, 1997: Global precipitation: A 17-year monthly analysis based on gauge observations, satellite estimates, and numerical outputs. Bull. Amer. Meteor. Soc., 78, 2539-2558.

Yasunari, T., and Y. Seki, 1992: Role of the Asian monsoon on the interannual variability of the global climate system. J. Meteor. Soc. Japan, 70, 177-189.

Yeh, M.-C., and T.-C. Chen, 2000: Seasonal variation of the rainfall over Taiwan. Int. J. Climatol., 20, 803-809.

Young, J. A., 1987: Physics of monsoons: The current view. Monsoons, J. S. Fein and P. L. Stephens, Eds., John Wiley and Sons, 211-243.

Yu, J.-Y., and J. D. Neelin, 1994: Modes of tropical variability under convective adjustment and the Madden-Julian oscillation. Part II: Numerical results. J. Atmos. Sci., 51, 1895-1914.

—, and 1997: Analytic approximation for moist convectively adjusted regions. J. Atmos. Sci., 54, 1054-1063.

Zeng, N., and J. D. Neelin, 1999: A land-atmosphere interaction theory for the tropical deforestation problem. J. Climate, 12, 857-872.

,-- , and C. Chou, 2000: A quasi-equilibrium tropical circulation model-Implementation and simulation. J. Atmos. Sci., 57, 1767-1796.

Zhang, R., and A. Sumi, 2002: Moisture circulation over East Asia during El Niño episode in northern winter, spring and autumn. J. Meteor. Soc. Japan, 80, 213-227.

,$- \ldots$, and M. Kimoto, 1996: Impact of El Niño on the East Asian monsoon: A diagnostic study of the '86/87 and ' $91 / 92$ events. J. Meteor. Soc. Japan, 74, 49-62.

- — - , and —_ 1999: A diagnostic study of the impact of El Niño on the precipitation in China. Adv. Atmos. Sci., 16, 229-241.

Zhang, Y., K. R. Sperber, and J. S. Boyle, 1997: Climatology and interannual variation of the East Asian winter monsoon: Results from the 1979-95 NCEP-NCAR reanalysis. Mon. Wea. Rev., 125, 2605-2619. 